\title{
ENSAIOS DE VARIEDADES DE MANDIOCA NA ESTAÇÃO EXPERIMENTAL DE UBATUBA
}

\author{
Edgard S. Normanha
}

Olavo J. Boock

\section{INTRODUÇÃO}

Com o fim de apresentarmos os resultados obtidos na experimentação de algumas variedades de mandioca na zona de Ubatuba --.- Litoral Norte do Estado de São Paulo - no tocante à sua produção bruta de raizes e o rendimento em farinha de mesa, damos, no presente trabalho, as conclusões a que chegamos após estudos feitos de 1937 a 1942.

Naquela região são cultivadas, por pequenos lavradores, hà muitos anos, diferentes variedades de mandioca. Fazem com elas a farinha de mesa, que é quase toda consumida na própria zona como parte integrante da alimentação dos habitantes do lugar.

\section{A CULTURA}

Em terrenos baixos, sujeitos ao encharcamento, ou naqueles arenosos, muito próximos às praias, as plantações são comumente feitas em grandes leiras de terra, a que chamam de "matumbos" ou "valos". Aquí, as manivas, com 15 a $20 \mathrm{~cm}$ de comprimento, são plantadas inclinadas e com um terço para fora.

As leiras ora são pequenas, ora grandes, podendo estas possuir uma ou mais fileiras de plantas. Os grandes "matumbos" são mais usados nos terrenos de beira de praia.

Outras vezes o plantio é feito plantando as manivas em posição inclinada e com $1 / 3$ para fora, numa porção de terra elevada com um golpe de enxada (fig. I).

\section{VARIEDADES CULTIVADAS}

São as seguintes as principais variedades de mandioca existentes nas pequenas lavouras da região de Ubatuba: 


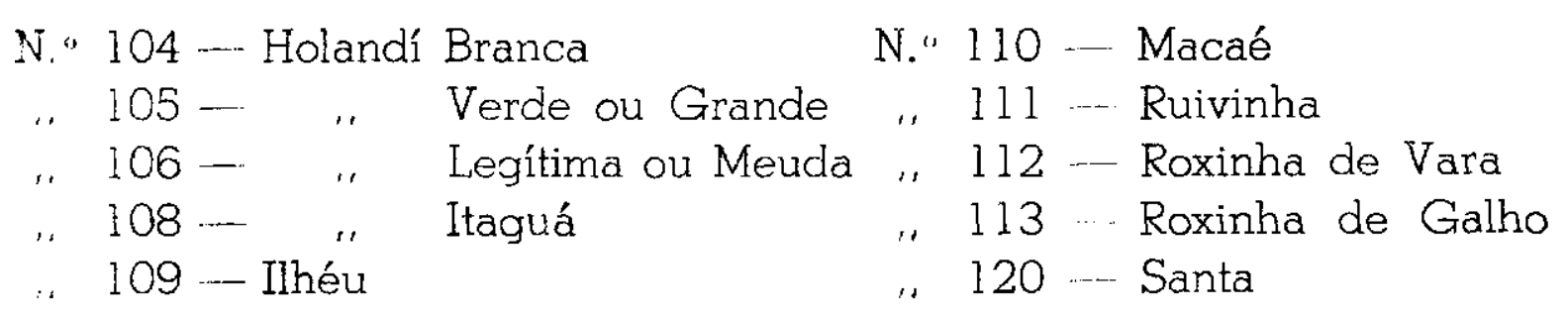

Os números acima se referem às fichas de registo na Secção de Raizes e.Tubérculos.

Com exceção da variedade Santa, as demais são tidas como venenosas. Todas são usadas para o fabrico da farinha de mesa, sendo aquela tambem utilizada para mesa (raizes cozidas), fornecendo boas raizes e de bom paladar. A sua farinha tem como desvantagem apresentar muito maior percentagem de fibras que a das demais.

As variedades Ilhéu e Ruivinha, são de porte baixo, possuindo ramas cinza-brancacentas, e raizes com película clara, delicada, apresentando manchas violáceas; a casca e a polpa são brancas.

As variedades Santa, Roxa de Vara e Roxa de Galho, possuem raizes com película parda e áspera, sendo a casca de cor roxa mais ou menos intensa. As ramas da variedade Santa são pardo-avermelhadas, e as das Roxa de Vara e Roxa de Galho são roxo-escuras.

As demais variedades apresentam ramas pardo-esverdeadas, raizes com película parda áspera, sendo a casca e a polpa brancas.

\section{APRECIAĢÃO DO SOLO}

As plantações de mandioca, na região de Ubatuba, são feitas em terrenos ora planos, ora acidentados, em morros, e, às vezes, em terras bem próximas às praias como já dissemos, muito arenosas e pobres.

Os dados que apresentamos, a seguir, constituem os resultados obticios na análise sumária de 2 amostras de terra, retiradas de lavouras de mandioca próximas à praia, e foram executadas pela Secção de Química Aorrícola, do Instituto Agronômico.

Terra N.

24.851

24.852

Umidade higroscópica ... 1,228\%

$0,112 \%$

Perda ao rubro

$1,011 \%$

$0,341 \%$

Ácido fosfórico

$0,026 \%$

$0,019 \%$

Óxido de cálcio

$0,053 \%$

$0,015 \%$

Óxido de potássio

$0,172 \%$

$0,011 \%$

Azoto total

$0,0280 \%$

$0,021 \%$

Acidez $\mathrm{pH}$

6,34

5,73 


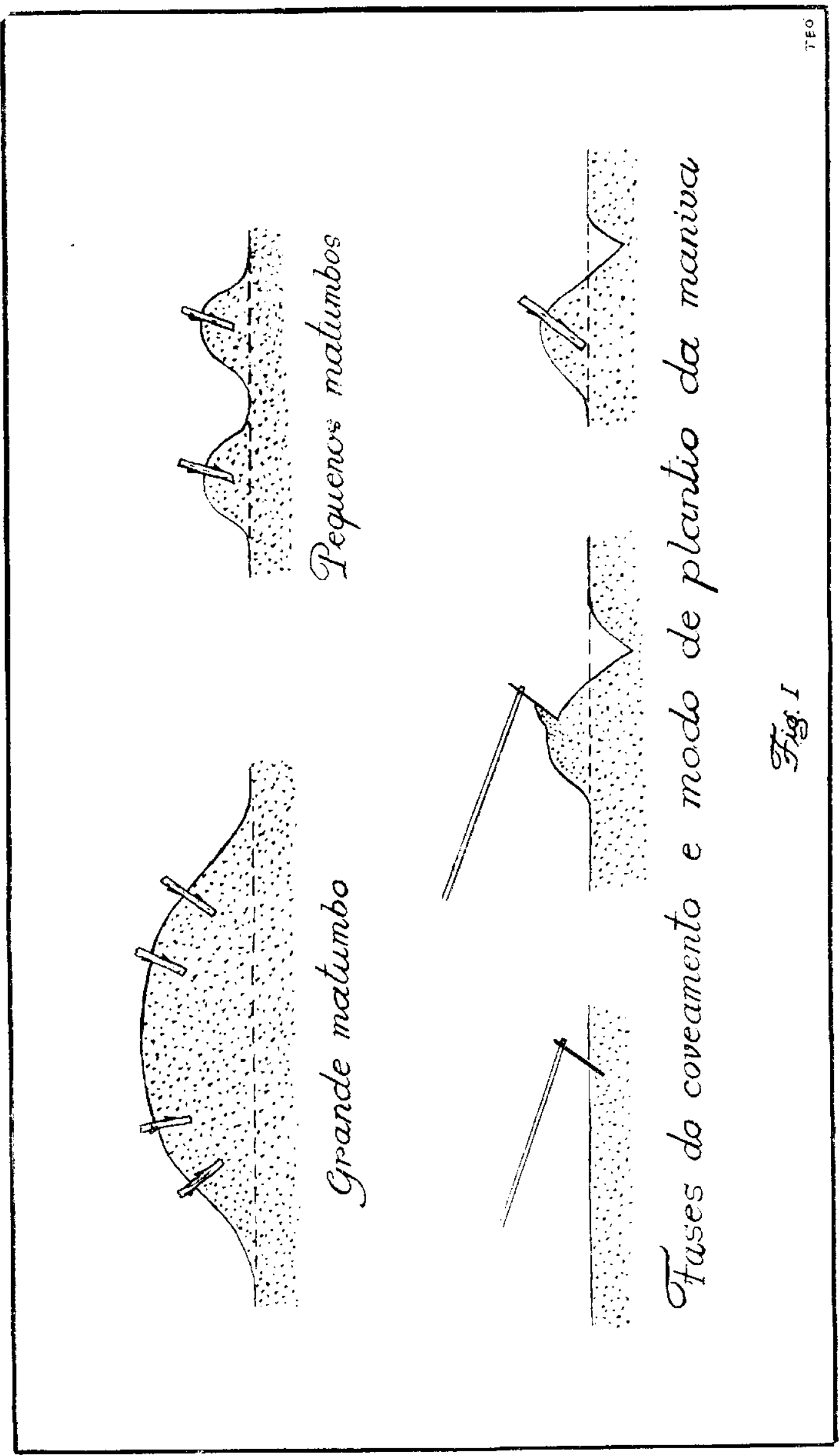


Do local em que se instalaram os ensaios, na Estação Experimental, foram tambem retiradas 6 amostras de terra, as quais foram analisadas por aquela Secção, sob os números de 43.734 a 43.739. As médias dos resultados obtidos na análise sumária, damos na relação abaixo:

Umidade higroscópica . . 3,339\%

Perda ao rubro ...... 8,631\%

Ácido fosfórico . . . . . . . 0,037\%

Óxido de cálcio ...... 0,134\%

Óxido de potássio ...... 0,450\%

Azoto total ......... 0,152\%

Acidez pH ......... 5,31

\section{APRE:CIAÇÃO DO CLIMA}

Chuvas - Obtivemos da Seç̧ão de Meteorologia, do Instituto Agronômico, os dados relativos às chuvas e às temperaturas mensais, de janeiro de 1937 a dezembro de 1941, tomados da localidade de Ubatuba.

O quadro I apresenta, para cada mês, de 1937 a 1941, as médias em milímetros de chuvas, os erros "standard" da distribuição, e os cceficientes de variabilidade.

\section{QUADRO I \\ QUADRO I}

\section{E S ES}

Janeiro.

Fevereiro

Março

Abril

Maio

Junho

Julho

Agosto

Setembro.

Outubro

Novembro

Dezembro 
O mês que acusou menor média de precipitações foi o de junho, com 81,8 milímetros. O total anual foi superior a $2.500 \mathrm{~mm}$.

Os erros "standard" da distribuição são elevados para quase todos os meses, e os coeficientes de variabilidade mostram que foi grande a variação das precipitações para os mesmos meses, de um ano para outro. Os meses que menos variação apresentaram foram os de outubro e dezembro, com coeficientes de variabilidade respectivamente iguais a $24,1 \%$ e $15,1 \%$.

Temperaturas - $O$ quadro II mostra as médias mensais de temperaturas (graus centígrados), tambem durante os anos de 1937 a 1941, na localidade de Ubatuba.

Conforme se pode ver, a variação havida, de mês para mês, segue a regra geral, para todo o Estado, isto é, decresce de janeiro para junho, subindo depois até dezembro. Os valores extremos das médias foi de 18,6 graus em junho até 24,6 em fevereiro.

QUADRO II

\begin{tabular}{|c|c|c|c|}
\hline MESES & $\begin{array}{c}\text { Tempera- } \\
\text { turas }\end{array}$ & MESES & $\begin{array}{c}\text { Tempera- } \\
\text { turas }\end{array}$ \\
\hline Janeiro & 24,4 & Julho ... & 17,8 \\
\hline Fevereiro & 24,6 & Agosto & 19,0 \\
\hline Março ........ & 24,3 & Setembro & 19,0 \\
\hline Abril . . . . . . . & 22,7 & Outubro & 20,2 \\
\hline Maio ... & 20,5 & Novembro & 21,5 \\
\hline Junho. . . & 18,6 & Dezembro & 23,2 \\
\hline
\end{tabular}

Uma caraterização bastante clara e figurada do aspecto climático da região de Ubatuba, no decorrer das nossas experiências, pode ser vista no diagrama I, o qual foi feito segundo o processo indicado pelo Dr. W. Knoche (3).

Este autor estudou a meteorologia de numerosas regiões do mundo e estabeleceu um diagrama básico para a representação gráfica do tipo de clima de qualquer região.

O seu diagrama preenche, para o nosso caso, toda a sua finalidade.

Assim, podemos demarcar para cada mês, a sua situação termchídrica encontrada à base do cálculo para as precipitações médias mensais em milímetros e temperaturas médias mensais em graus Centígrados. 
As médias em questão foram obtidas, como já dissemos, a partir de dados bastante variáveis para os mesmos meses e de ano para ano, no período de 1937 a 1942.

Pela leitura dos dados que interpretam o climatograma, podemos ver que o clima daquela localidade foi, de 1937 a 1942, o seguinte:

quente e semi-úmido em junho:

bastante quente e úmido em maio, julho, agosto, setembro, outubro e novembro;

muito quente e úmido em fevereiro, abril e dezembro; e muito quente e muito úmido em janeiro e março.

A fórmula climatérica abreviada pelo método do Dr. W. Knoche, deduzida daquele gráfico, será:' '3Id; 3IIo; 3Id; estes números representam, respectivamente, as caraterísticas termo-pluviométricas dos meses de outubro (na primavera), janeiro (no verão) e do valor médio anual. Então, no decurso das experiências, o clima se mostrou, de um modo geral, bastante quente e úmido ( ${ }^{\mathrm{I}} \mathrm{I}^{\mathrm{d}}$ ).

A mandioca, que é uma planta de clima tropical e sub-tropical, ou melhor, quente e úmido, encontra na zona de Ubatuba, caraterísticas de clima favoráveis à sua cultura.

\section{ENSAIOS DE VARIEDADES}

Em 1937 iniciamos as experiências de variedades de mandioca na Estação Experimental de Ubatuba, com o plantio do 1." ensaio, no qual figuraram 9 variedades corıseguidas de diversos lavradores daquela zona.

\section{Plano geral dos ensaios :}

Canteiros: 4 linhas de 25 plantas cada uma;

Espaçamento: $1,20 \mathrm{~m}$ entre linhas e 0,60 m entre plantas, 2,40 m entre canteiros, de linha a linha.

Repetições: 4, ao acaso.

Sistema de plantio: comum, ou seja: manivas de $15 \mathrm{~cm}$ plantadas horizontalmente nos sulcos, cobertas com terra.

Sem adubação.

\section{$1 .^{\circ}$ ENSAIO}

Plantio em: 2 de agosto de 1937

Colheita em: julho de 1938

Ciclo vegetativo: 11 meses

Variedades estudadas: 


\section{Classificacão Climática}

\section{(DR. W. KnOCHE)}

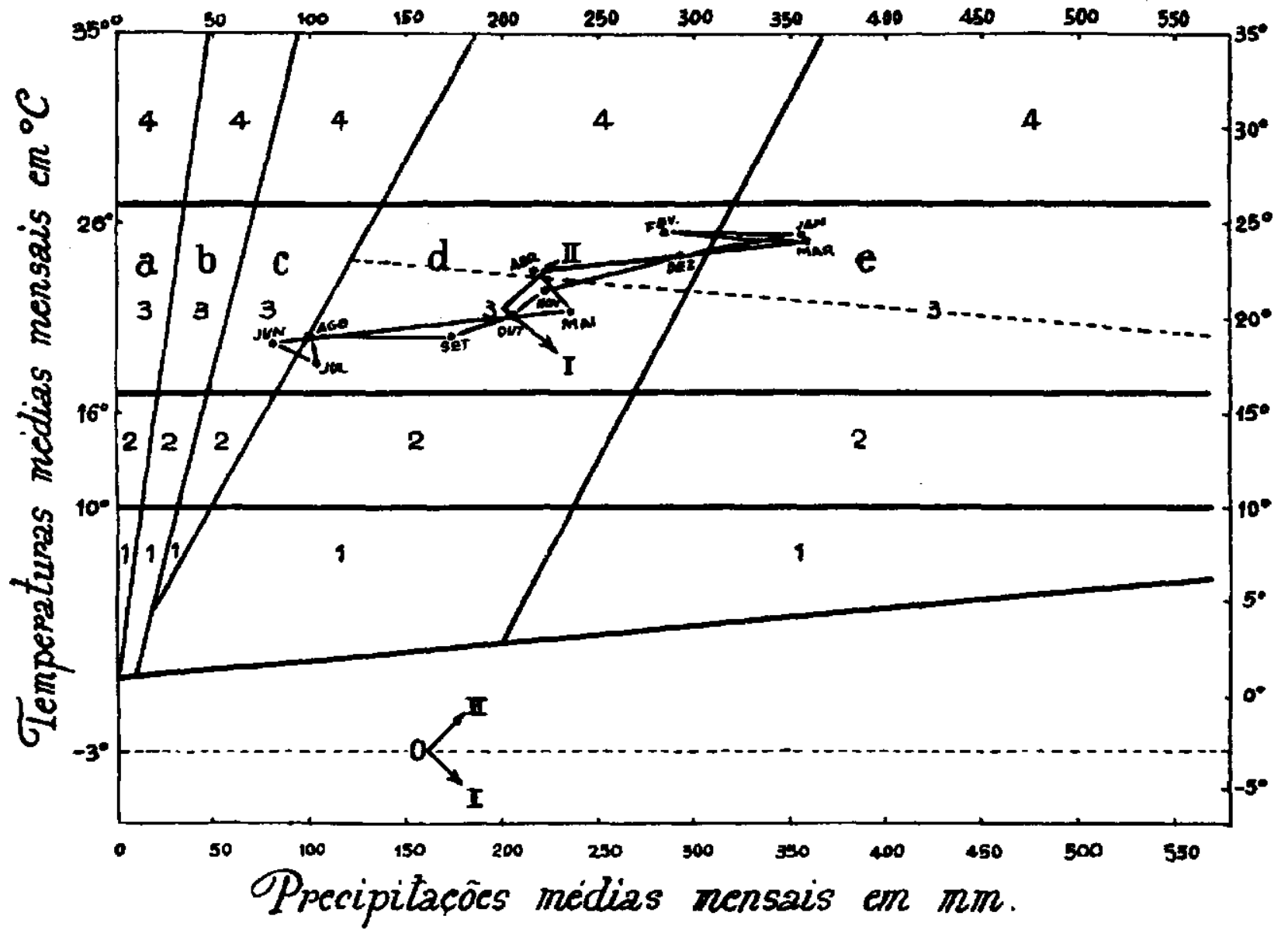

REgIÃo de UBATUBA-E.S.PAULO-BrasiL- $23^{\circ} 26{ }^{\circ} S, 45^{\circ} 5^{\prime} \mathrm{W}$ dE GREENWICH.

\begin{tabular}{|c|c|c|c|c|c|c|}
\hline$J_{A N}$. & $\beta_{\text {II }} e$ & $\begin{array}{l}\text { muito quente } e \\
\text { muito imido }\end{array}$ & JuN. & $3 c \mid$ & $\begin{array}{l}\text { quente e } \\
\text { semi-úmido }\end{array}$ & \multirow{5}{*}{ 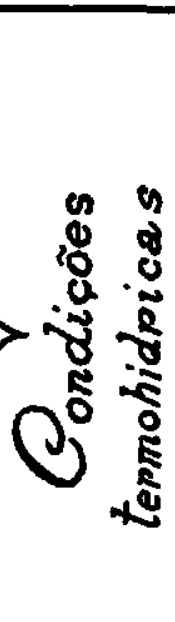 } \\
\hline FEV. & $3_{1} d$ & $\begin{array}{l}\text { muito quente } \\
\text { e imido }\end{array}$ & \multirow{3}{*}{$\begin{array}{l}\text { JUL. } \\
\text { AGO. } \\
\text { SET. } \\
\text { OUT. } \\
\text { NOV. }\end{array}$} & \multirow{3}{*}{$3_{\mathrm{I}} \mathrm{d}$} & \multirow{3}{*}{$\begin{array}{l}\text { bastante } \\
\text { quente } \\
\text { imida }\end{array}$} & \\
\hline & $\xi_{\text {III }} e$ & $\begin{array}{l}\text { muito quente } r \\
\text { muito uimidor. }\end{array}$ & & & & \\
\hline & $3_{\text {II }} \mathrm{d}$ & $\begin{array}{l}\text { muito quente } \\
\text { e imido. }\end{array}$ & & & & \\
\hline & $3_{1} d$ & $\begin{array}{l}\text { bastante quen } \\
\text { te e imido }\end{array}$ & $D_{E Z}$ & $3_{\pi} \mathrm{d}$ & $\begin{array}{l}\text { muito quente } \\
e \text { iemido. }\end{array}$ & \\
\hline
\end{tabular}



N. ${ }^{\circ} 108$ - Holandí Itaguá N. 105 - Holandí Verde ou Grande
" 109 - Ilhéu
. 112 - Roxa de Vara
"113 - Roxa de Galho
" 110 - Macaé
' 104 - Holandí Branca
, 111 - Ruivinha
. 120 - Santa

"stand" e o aspecto vegetativo das plantas foram muito bons para todas as variedades.

As produções de raizes obtidas nesse ensaio e os seus cálculos estatísticos acham-se respectivamente nos quadros III e IV. Estes cálculos estatísticos, bem como os demais deste trabalho, foram feitos segundo os métodos de Fisher (1) e Brieger (2)

As produções em Ton de raizes por alqueire $(24.200 \mathrm{~m} 2)$ foram boas, pois, no planalto, colheitas de 30-40 Ton por alqueire, para culturas de um ciclo vegetativo, são econômicas. 


\section{QUADRO III}

\begin{tabular}{|c|c|c|c|c|c|c|c|}
\hline \multirow{3}{*}{$\begin{array}{l}\text { Var. } \\
\text { N.' }\end{array}$} & \multicolumn{4}{|c|}{$\mathrm{Kg}$ por canteiro } & \multirow{3}{*}{$\begin{array}{c}\text { Médias } \\
\text { Kg }\end{array}$} & \multirow{2}{*}{\multicolumn{2}{|c|}{ Ton }} \\
\hline & \multicolumn{4}{|c|}{ SERIES } & & & \\
\hline & $I^{\text {a }}$ & $2^{a}$ & $3^{a}$ & $4^{a}$ & & Ha. & Alg. \\
\hline 108 & 104,5 & 109,3 & 123,5 & 102,0 & 109,8 & 15,2 & 36,8 \\
\hline 109 & 96,5 & 114,5 & 110,5 & 104,0 & 106,4 & 14,8 & 35,8 \\
\hline 112 & 84,5 & 122,1 & 115,0 & 97,0 & 104,6 & 14,5 & 35,1 \\
\hline 110 & 97,5 & 89,0 & 123,5 & 100,0 & 102,5 & 14,2 & 34,4 \\
\hline 111 & 85,0 & 98,0 & 133,0 & 93,0 & 102,2 & 14,2 & 34,4 \\
\hline 105 & 91,1 & 92,0 & 112,8 & 103,2 & 99,8 & 13,8 & 33,4 \\
\hline 113 & 89,0 & 109,0 & 94,5 & 103,5 & 99,0 & 13,7 & 33,1 \\
\hline 104 & 83,5 & 94,5 & 99,5 & 97,5 & 93,7 & 13,0 & 31,5 \\
\hline 120 & 75,0 & 95,0 & 91,5 & 101,0 & 90,6 & 12,6 & 30,5 \\
\hline
\end{tabular}

\section{QUADRO IV}

ANÁLISE DA VARIANCE

\begin{tabular}{|c|c|c|c|c|c|c|}
\hline VARIAÇÃO & $\mathrm{Sd}^{2}$ & $\mathrm{nf}_{\mathrm{f}}$ & $s^{2}$ & $s$ & $\vartheta$ & \\
\hline Total & 5580,84 & 35 & 159,453 & 12,59 & 1,31 & \multirow{4}{*}{ n.s. } \\
\hline Variedades & 1158,42 & 8 & 144,803 & 12,03 & 1,25 & \\
\hline Repetições & 2193,42 & 3 & 731,140 & 27,04 & 2,80 & \\
\hline Resíduo & 2229,00 & 24 & 92,875 & 9,64 & & \\
\hline
\end{tabular}

n.s. $=$ não significativo $\mathrm{s}_{\mathrm{v}}^{-}=4,82$

Não houve diferença estatística entre as variedades.

As raizes colhidas foram industrializadas em farinha de mesa, pelo processo alí usado sendo as suas produções tambem analisadas estatísticamente. 
$O$ resultado foi o seguinte (quadros $V$ e VI) :

\section{QUADRO V}

\begin{tabular}{|c|c|c|c|c|c|c|c|c|}
\hline \multirow{3}{*}{$\begin{array}{l}\text { Var. } \\
\text { N." }\end{array}$} & \multicolumn{4}{|c|}{$\mathrm{Kg}$ por canteiro } & \multirow{3}{*}{$\begin{array}{c}\text { Médias } \\
\text { Kg }\end{array}$} & \multirow{2}{*}{\multicolumn{2}{|c|}{ Ton por }} & \multirow{3}{*}{$\begin{array}{l}\% \text { de } \\
\text { farinha }\end{array}$} \\
\hline & \multicolumn{4}{|c|}{ SER IES } & & & & \\
\hline & $l^{a}$ & $2:$ & $3:$ & $4^{: t}$ & & $\mathrm{Ha}$. & Alg. & \\
\hline 108 & 24,7 & 38,5 & 21,6 & 28,0 & 28,2 & 3,92 & 9,49 & 25,7 \\
\hline 113 & 20,0 & 30,0 & 32,0 & 30,0 & 28,0 & 3,89 & 9,41 & 28,3 \\
\hline 109 & 22,3 & 32,1 & 31,3 & 26,0 & 27,9 & 3,87 & 9,36 & 26,2 \\
\hline 105 & 27,0 & 30,2 & 21,7 & 28,3 & 26,8 & 3,72 & 9,00 & 26,8 \\
\hline 111 & 25,6 & 21,0 & 35,0 & 25,3 & 26,7 & 3,71 & 8,98 & 26,1 \\
\hline 110 & 26,0 & 24,0 & 32,5 & 23,5 & 26,5 & 3,68 & 8,90 & 25,8 \\
\hline 104 & 23,0 & 23,4 & 26,7 & 23,5 & 24,1 & 3,35 & 8,11 & 25,7 \\
\hline 112 & 20,5 & 22,0 & 23,0 & 26,5 & 23,0 & 3,19 & 7,72 & 22,0 \\
\hline 120 & 13,1 & 19,0 & 18,0 & 21,0 & 17,8 & 2,47 & 5,98 & 19,6 \\
\hline
\end{tabular}

QUADRO VI

ANÁLISE DA VARIANCE

\begin{tabular}{|c|c|c|c|c|c|c|}
\hline VARIAÇÃO & $\mathrm{Sd}^{2}$ & $\mathrm{nf}$ & $s^{2}$ & $s$ & $\vartheta$ & \\
\hline Total ........ & 937,49 & 35 & 26,79 & 5,2 & 1,2 & \\
\hline Variedades... & 365,36 & 8 & 45,67 & 6,8 & 1,5 & n.s. \\
\hline Repetições . . . & 113,01 & 3 & 37,67 & 6,1 & 1,4 & \\
\hline Resíduo. & 459,12 & 24 & 19,13 & 4,4 & & \\
\hline
\end{tabular}

n.s. $=$ não significativo $\mathbf{s}_{\mathrm{v}}^{-}=2,2$ 
Tambem não houve diferença significativa entre as produções de farinha, como não houve entre as de raizes.

\section{8." ENSAIO}

Plantio em: 24 de junho de 1938

Colheita em: setembro de 1939

Ciclo vegetativo: 1 ano e 3 meses

As variedades estudadas neste ensaio foram, alem das do anterior, mais a de n.' l .... Vassourinha ...., (foto 1) a mais cultivada no Estado de São Paulo, e alí introduzida pela Seç̧ão de Raizes e Tubérculos, em 1938, e a de n. ${ }^{\circ} 106$-- Holandí Legítimāda própria região.

Nesta experiência e nas seguintes, pudemos comparar a produção das variedades cultivadas na região de Ubatuba com a da "Vassourinha", a mais difundida no Estado de São Paulo.

O "stand" foi bom para todas as variedades. Os canteiros da de n. 109 - Ilhéu - apresentaram mistura com a variedade n." 111 Ruivinha. Por esta razão a variedade em apreço (n." 109) não foi considerada nos cálculos.

Os dados de produção acham-se no quadro VII e gráfico I e a sua análise no quadro VIII.

As produções obtidas foram econômicas, para todas as variedades e, conforme vamos ver, a variedade n." l - Vassourinha foi superior em produção de raizes, porem seu rendimento em farinha não foi o melhor. Este coube às variedades n.os 108-H. Itaguá e 104 H. Branca. 
QUADRO VII

\begin{tabular}{|c|c|c|c|c|c|c|c|}
\hline \multirow{3}{*}{$\begin{array}{l}\text { Var. } \\
\text { N. }{ }^{\circ}\end{array}$} & \multicolumn{4}{|c|}{ Kg por canteiro } & \multirow{3}{*}{$\begin{array}{c}\text { Médias } \\
\text { Kg }\end{array}$} & \multirow{2}{*}{\multicolumn{2}{|c|}{ Ton }} \\
\hline & \multicolumn{4}{|c|}{ SÉRIES } & & & \\
\hline & $1^{a}$ & $2^{a}$ & $3^{n}$ & $4^{a}$ & & $\mathrm{Ha}$. & Alq. \\
\hline 1 & 125,0 & 123,0 & 114,6 & 161,8 & 131,1 & 18,2 & 44,0 \\
\hline 110 & 103,3 & 111,2 & 122,1 & 130,6 & 116,8 & 16,2 & 39,2 \\
\hline 105 & 131,6 & 124,1 & 108,8 & 100,9 & 116,3 & 16,1 & 39,0 \\
\hline 112 & 128,0 & 109,9 & 103,8 & 107,8 & 112,4 & 15,6 & 37,7 \\
\hline 108 & 105,0 & 120,0 & 108,0 & 91,5 & 106,1 & 14,7 & 35,6 \\
\hline 113 & 115,3 & 113,2 & 97,3 & 98,3 & 106,0 & 14,7 & 35,6 \\
\hline 106 & 101,6 & 97,8 & 117,6 & 105,7 & 105,7 & 14,7 & 35,6 \\
\hline 120 & 107,0 & 115,8 & 91,8 & 104,8 & 104,8 & 14,5 & 35,1 \\
\hline 111 & 111,8 & 95,3 & 106,3 & 85,0 & 99,6 & 13,8 & 33,4 \\
\hline 104 & 109,4 & 78,2 & 102,5 & 95,5 & 96,4 & 13,4 & 32,4 \\
\hline
\end{tabular}

\section{QUADRO VIII}

ANÁLISE DA VARIANCE

\begin{tabular}{|c|c|c|c|c|c|c|}
\hline VARIAÇÃO & $\mathrm{Sd}^{2}$ & $\mathrm{nf}_{\mathrm{f}}$ & $s^{2}$ & $\mathrm{~s}$ & $\vartheta$ & \\
\hline Total & 8464,03 & 39 & 217,03 & 14,73 & 1,13 & , \\
\hline Variedades & 3617,48 & 9 & 401,94 & 20,05 & 1,54 & s. \\
\hline Repetições ... & 255,54 & 3 & 85,18 & 9,23 & 0,71 & \\
\hline Resíduo & 4591,01 & 27 & 170,04 & 13,04 & & \\
\hline
\end{tabular}

$\mathrm{s.}=$ significativo $\mathrm{s}_{\mathrm{v}}=6,52$

Para $\mathrm{P}=5 \%$, a diferença mínima significativa é $22,5 \mathrm{Kg}$ por canteiro. A variedade "Vassourinha" foi superior em produção às de n. ${ }^{\circ} \mathrm{S}$ $104,111,120,106,113$ e 108. 


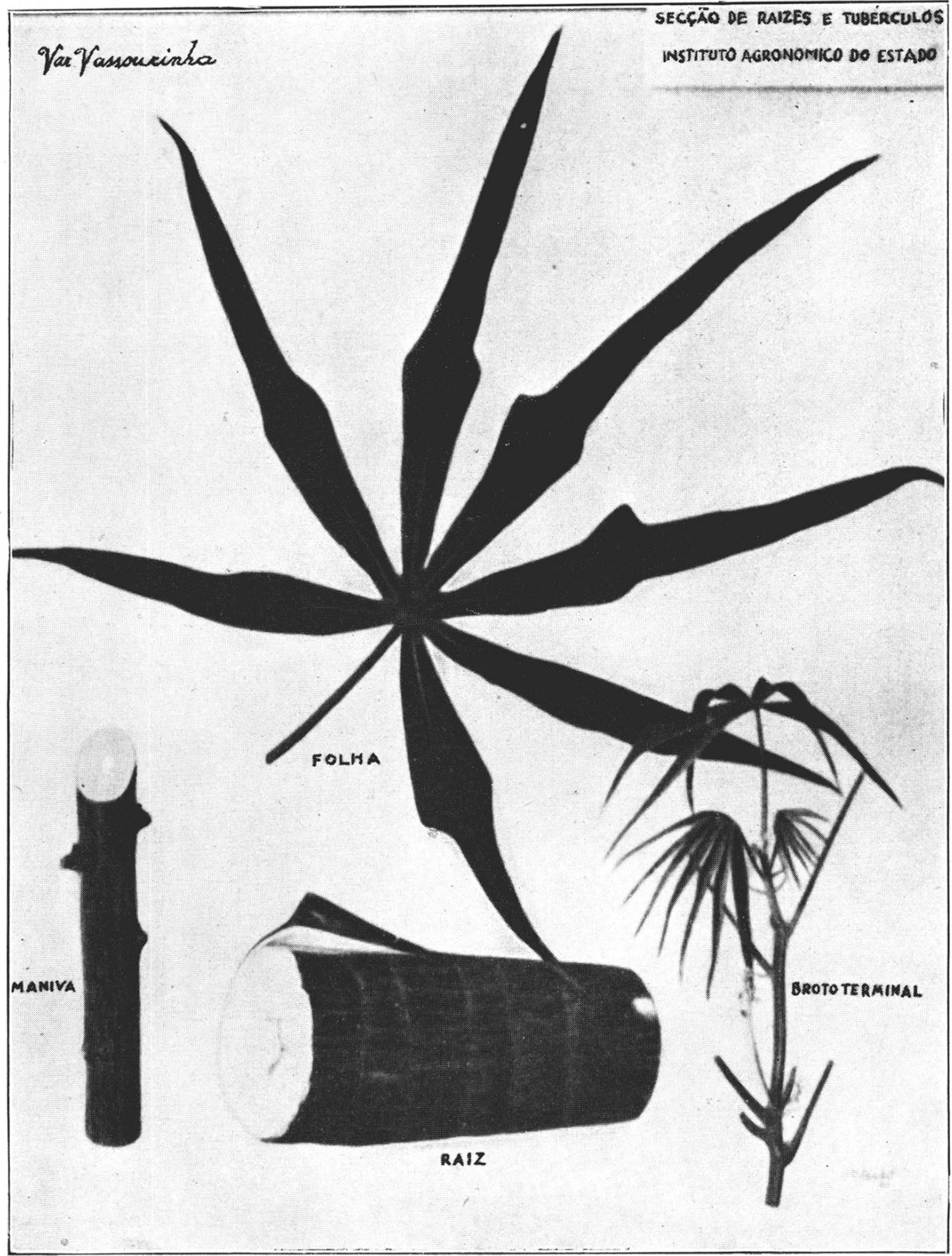

Foto 1

Variedade "Vassourinha" 


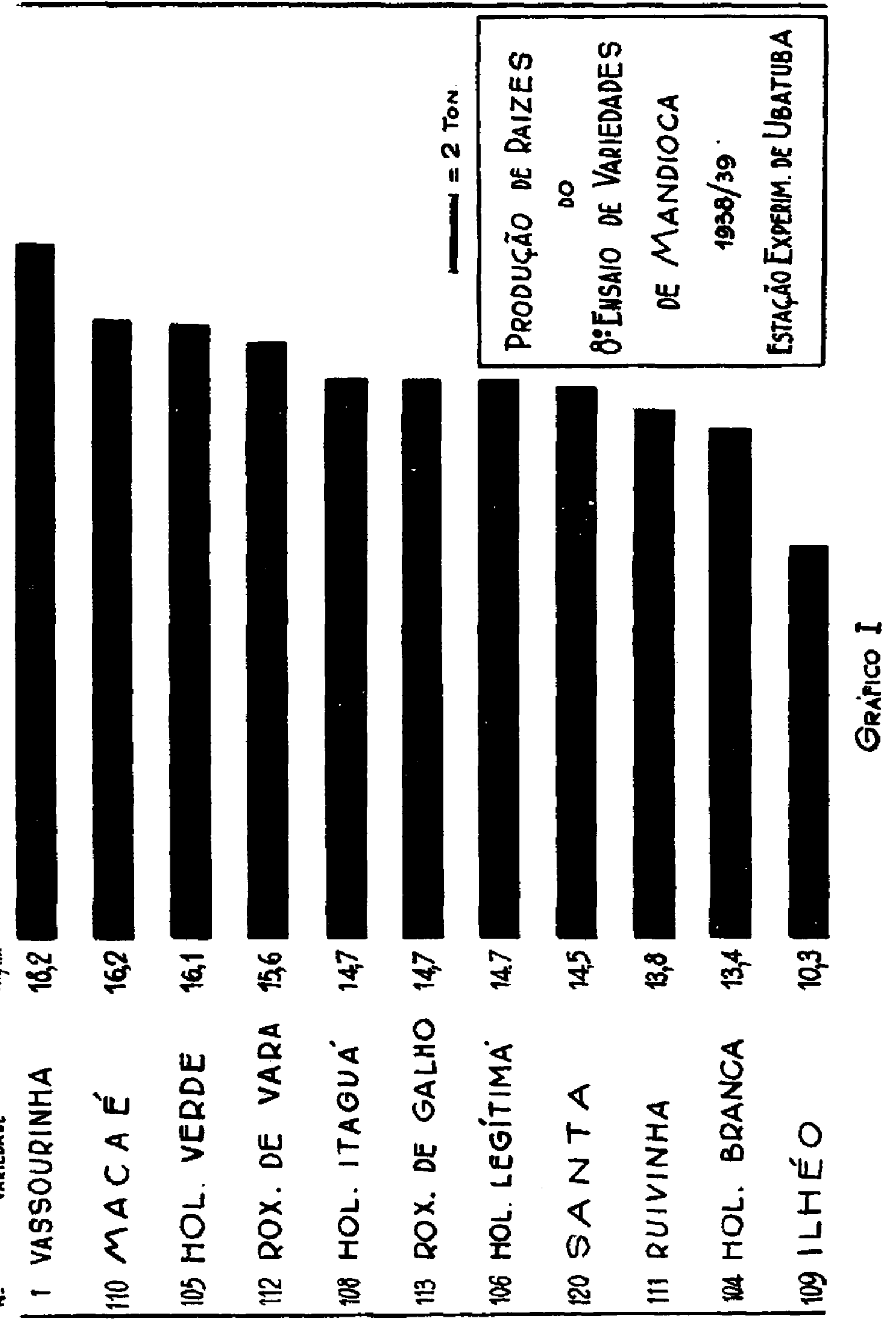


O cálculo da produção de farinha de mesa, por variedade, forneceu os seguintes dados (quadro IX e X)

\section{QUADRO IX}

\begin{tabular}{|c|c|c|c|c|c|c|c|c|}
\hline \multirow{3}{*}{$\begin{array}{l}\text { Var. } \\
\text { N. }\end{array}$} & \multicolumn{4}{|c|}{ Kg por canteiro } & \multirow{3}{*}{$\begin{array}{l}\text { Médias } \\
\text { Kg }\end{array}$} & \multirow{2}{*}{\multicolumn{2}{|c|}{ Ton por }} & \multirow{3}{*}{$\begin{array}{l}\% \text { de } \\
\text { farinha }\end{array}$} \\
\hline & \multicolumn{4}{|c|}{ SÉRIES } & & & & \\
\hline & $1^{a}$ & $2^{a}$ & $3^{n}$ & $4^{a t}$ & & $\mathrm{Ha}$. & Alg. & \\
\hline 1 & 28,0 & 27,5 & 25,6 & 34,5 & 28,9 & 4,01 & 9,70 & 22,0 \\
\hline 108 & 29,1 & 32,0 & 27,5 & 25,1 & 28,4 & 3,94 & 9,53 & 26,8 \\
\hline 110 & 22,6 & 28,8 & 27,1 & 31,2 & 27,4 & 3,80 & 9,20 & 23,4 \\
\hline 113 & 34,1 & 30,2 & 21,3 & 24,0 & $27 ; 4$ & 3,80 & 9,20 & 25,8 \\
\hline 105 & 21,9 & 33,2 & 26,8 & 27,4 & 27,3 & 3,79 & 9,17 & 23,5 \\
\hline 106 & 28,0 & 24,8 & 28,2 & 26,8 & 27,0 & 3,75 & 9,07 & 25,5 \\
\hline 104 & 28,0 & 20,0 & 25,4 & 27,1 & 25,1 & 3,49 & 8,44 & 26,0 \\
\hline 112 & 29,6 & 24,0 & 22,7 & 23,4 & 24,9 & 3,46 & 8,37 & 22,1 \\
\hline 111 & 27,2 & 22,0 & 23,9 & 22,1 & 23,8 & 3,30 & 8,00 & 23,9 \\
\hline 120 & 20,8 & 21,2 & 17,6 & 25,0 & 21,2 & 2,94 & 7,11 & 20,2 \\
\hline
\end{tabular}

QUADRO X

ANALISE DA VARIANCE

\begin{tabular}{|c|c|c|c|c|c|c|}
\hline VARIAÇÃO & $\mathrm{Sd}^{2}$ & $\mathrm{n}_{\mathrm{i}}$ & $\mathrm{s}^{2}$ & $s$ & $\vartheta$ & \\
\hline Total & 600,56 & $39^{\circ}$ & 15,4 & 3,92 & 1,18 & \\
\hline Variedades. & 179,09 & 9 & 19,9 & 4,46 & 1,34 & n.s. \\
\hline Repetições . & 32,88 & 3 & 11,0 & 3,32 & 1,00 & \\
\hline Resíduo... & 388,59 & 27 & 14,4 & 3,79 & & \\
\hline
\end{tabular}

n.s. = não significativo $\mathrm{s}_{\mathrm{v}}^{-}=1,90$

Este ensaio, a-pesar-de ter acusado diferença estatística na produção de raizes entre variedades, não acusou quanto à produção de farinha. 


\section{ENSAIO}

Plantio em : 23 de junho de 1938

Colheita em: fins de junho de 1940

Ciclo vegetativo: 2 anos

Variedades estudadas: as mesmas do $8 .^{\circ}$ ensaio.

Os dados da colheita deste ensaio nos permitiram comparar as produções das variedades em estudo, com 1 e 2 ciclos vegetativos - $8 .^{\circ}$ e $7 .^{\circ}$ ensaios respectivamente.

O "stand" foi, de uma maneira geral, bom para todas as variedades. Para as de n. ${ }^{\circ} 109$ - Ilhéu - e n. ${ }^{\circ} 111$ - Ruivinha - entretanto, houve algumas falhas.

Os resultados da colheita acham-se nos quadros XI e XII e gráfico II QUADRO XI

\begin{tabular}{|c|c|c|c|c|c|c|c|}
\hline \multirow{3}{*}{$\begin{array}{l}\text { Var. } \\
\text { N.o }\end{array}$} & \multicolumn{4}{|c|}{ - Kg por canteiro } & \multirow{3}{*}{$\begin{array}{c}\text { Médias } \\
\mathrm{Kg}\end{array}$} & \multirow{2}{*}{ Tor } & \multirow{2}{*}{ por } \\
\hline & \multicolumn{4}{|c|}{ SERIES } & & & \\
\hline & $l^{\mathfrak{a}}$ & $2^{a}$ & $3^{a}$ & $4^{a}$ & & $\mathrm{Ha}$. & Alq. \\
\hline 1 & 183,0 & 203,0 & 149,0 & 141,3 & 169,1 & 23,5 & 56,9 \\
\hline 120 & 140,0 & 142,5 & 142,8 & 100,0 & 131,3 & 18,2 & 44,0 \\
\hline 108 & 131,0 & 119,0 & 111,5 & $\cdot 77,0$ & 109,6 & 15,2 & 36,8 \\
\hline 104 & 72,0 & 100,2 & 106,0 & 139,5 & 104,4 & 14,5 & 35,1 \\
\hline 105 & 114,5 & 107,3 & 109,5 & 84,1 & 103,9 & 14,4 & 34,8 \\
\hline 112 & 111,5 & 107,2 & 94,5 & 91,0 & 101,1 & 14,0 & 33,9 \\
\hline 106 & 80,5 & 105,5 & 112,0 & 93,8 & 98,0 & 13,6 & 32,9 \\
\hline 113 & 115,0 & 125,0 & $-76,0$ & 69,0 & 96,3 & 13,4 & 32,4 \\
\hline 110 & 81,0 & 84,5 & 114,0 & 94,5 & 93,5 & 13,0 & 31,5 \\
\hline 111 & 78,8 & 67,5 & 106,4 & 60,2 & 78,2 & 10,9 & 26,4 \\
\hline 109 & 74,0 & 78,5 & 73,5 & 65,0 & 72,8 & 10,1 & 24,4 \\
\hline
\end{tabular}

QUADRO XII

ANALISE DA VARIANCE.

\begin{tabular}{|c|c|c|c|c|c|c|}
\hline VARIAÇÃO & $\mathrm{Sd}^{2}$ & $\mathrm{n}_{\mathrm{f}}$ & $\mathrm{s}^{2}$ & $\mathbf{S}$ & $\vartheta$ & \\
\hline $\begin{array}{l}\text { Total ..... . } \\
\text { Variedades . } \\
\text { Repetições . } \\
\text { Resíduo . . . . }\end{array}$ & $\begin{array}{r}40887,56 \\
27407,61 \\
2638,02 \\
10841,93\end{array}$ & $\begin{array}{r}43 \\
10 \\
3 \\
30\end{array}$ & $\begin{array}{r}950,87 \\
2740,76 \\
879,34 \\
361,40\end{array}$ & $\begin{array}{l}30,8 \\
52,4 \\
29,7 \\
19,0\end{array}$ & $\begin{array}{l}1,6 \\
2,8 \\
1,6\end{array}$ & s. \\
\hline
\end{tabular}

s. = significativo. $\mathrm{s}_{\overline{\mathrm{v}}}=9,5$ 
Houve diferença significativa de produção entre as variedades, mesmo para $\mathrm{P}=1 \%$. Considerando apenas $\mathrm{P}=5 \%$, a diferença mínima significativa é de $32,9 \mathrm{Kg}$ para se comparar a produção de duas quaisquer variedades.

Conclusão deste ensaio:

Var. n. 1 "Vassourinha" superior a todas. Seguem-se, na ordem de importância : Var. n. ${ }^{\circ} 120$ - Santa,

¿ 106 - Holandí legítima

. 113 - Roxa de Galho

"110 - Macaé

"111-Ruivinha

" 109 - Ilhéu

As demais variedades apresentaram produções praticamente idênticas.

A análise dos dados obtidos da fabricação de farinha, com aquelas variedades, mostrou os seguintes resultados (quadros XIII e XIV). 

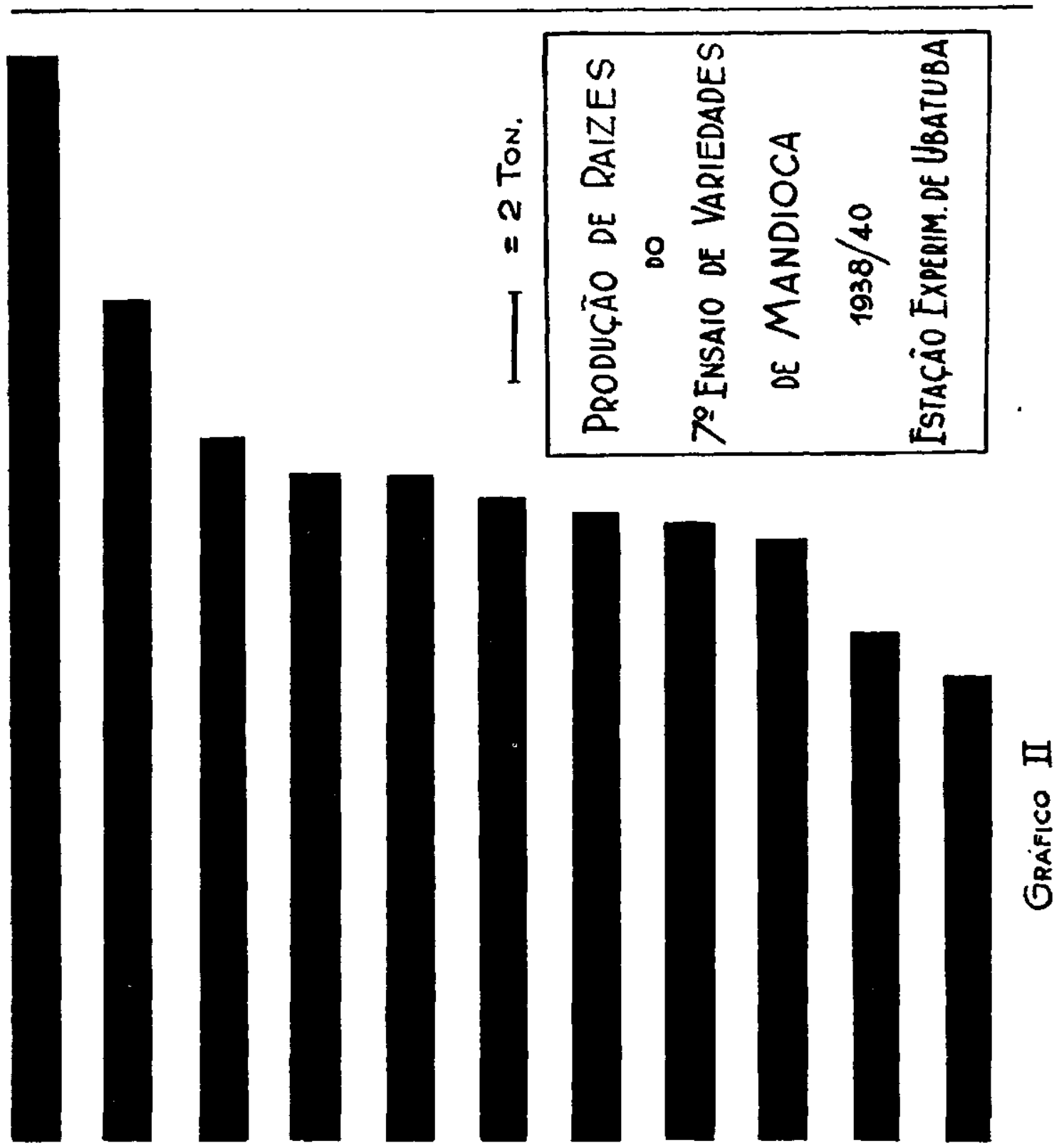

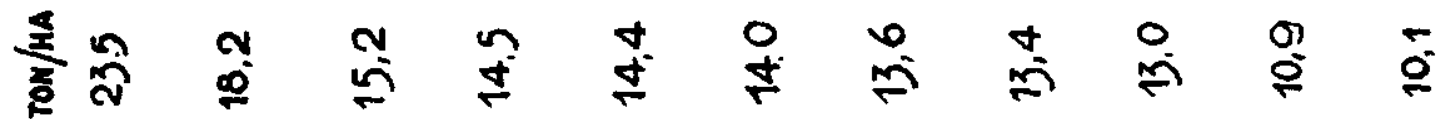

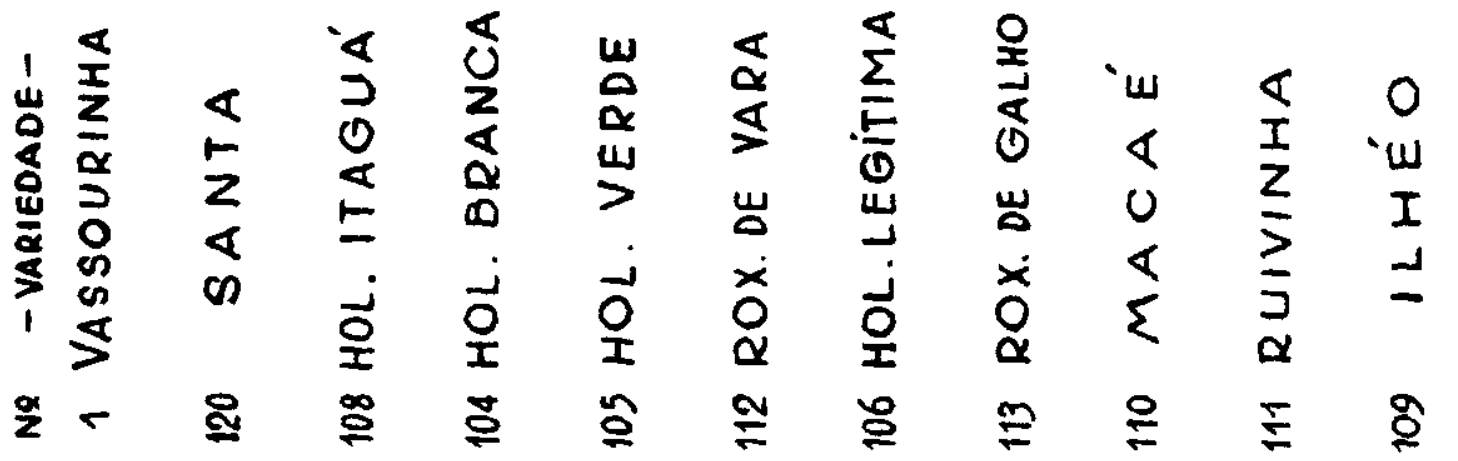




\section{QUADRO XIII}

\begin{tabular}{|c|c|c|c|c|c|c|c|c|}
\hline \multirow{3}{*}{$\begin{array}{l}\text { Var. } \\
\text { N. }{ }^{\circ}\end{array}$} & \multicolumn{4}{|c|}{$\mathrm{Kg}$ por canteiro } & \multirow{3}{*}{$\begin{array}{l}\text { Médias } \\
\text { Kg }\end{array}$} & \multirow{2}{*}{\multicolumn{2}{|c|}{ Ton por }} & \multirow{3}{*}{$\begin{array}{l}\% \text { de } \\
\text { farinha }\end{array}$} \\
\hline & \multicolumn{4}{|c|}{ SÉRIES } & & & & \\
\hline & $1^{a}$ & $2^{*}$ & $3^{a}$ & $4:$ & & Ha. & Alg. & \\
\hline 1 & 60,5 & 64,0 & 46,0 & 39,5 & 52,5 & 7,29 & 17,64 & 31,0 \\
\hline 120 & 40,0 & 42,5 & 40,0 & 30,5 & 38,2 & 5,30 & 12,83 & 29,1 \\
\hline 108 & 37,0 & 34,7 & 31,0 & 25,0 & 31,9 & 4,43 & 10,72 & 29,1 \\
\hline 105 & 35,5 & 34,0 & 32,0 & 24,8 & 31,6 & 4,39 & 10,62 & 30,4 \\
\hline 104 & 20,0 & 29,2 & 31,0 & 38,5 & 29,7 & 4,12 & 9,97 & 28,4 \\
\hline 106 & 21,5 & 32,5 & 34,0 & 29,0 & 29,2 & 4,05 & 9,80 & 29,8 \\
\hline 112 & 31,0 & 30,0 & 25,0 & 23,5 & 27,4 & 3,80 & 9,19 & 27,1 \\
\hline 113 & 30,0 & 36,0 & 22,5 & 20,5 & 27,2 & 3,78 & 9,15 & 28,2 \\
\hline 110 & 23,5 & 22,0 & 33,5 & 28,0 & 26,7 & 3,71 & 8,98 & 28,5 \\
\hline 111 & 24,5 & 21,0 & 29,5 & 17,0 & 23,0 & 3,19 & 7,72 & 29,4 \\
\hline 109 & 20,0 & 21,1 & 22,5 & 19,2 & 20,7 & 2,87 & 6,94 & 28,4 \\
\hline
\end{tabular}

QUADRO XIV

ANALISE DA VARIANCE

\begin{tabular}{|c|c|c|c|c|c|c|}
\hline VARIAÇ $\tilde{A} O$ & $\mathrm{Sd}^{2}$ & $n_{f}$ & $\mathrm{~s}^{2}$ & $s$ & $\theta$ & \\
\hline$\ldots \ldots$ & 4213,87 & 43 & 98,00 & 9,9 & 1,71 & \\
\hline Variedades. . & 2941,94 & 10 & 294,19 & 17,2 & 3,00 & $\mathrm{~s}$. \\
\hline Repetições . . & 250,75 & 3 & 83,58 & 9,1 & 1,57 & \\
\hline Resíduo..... & 1021,18 & 30 & 34,04 & 5,8 & & \\
\hline
\end{tabular}

$\mathrm{s} .=$ significativo. $\quad \mathrm{s}_{\mathrm{v}}=2,9$ 

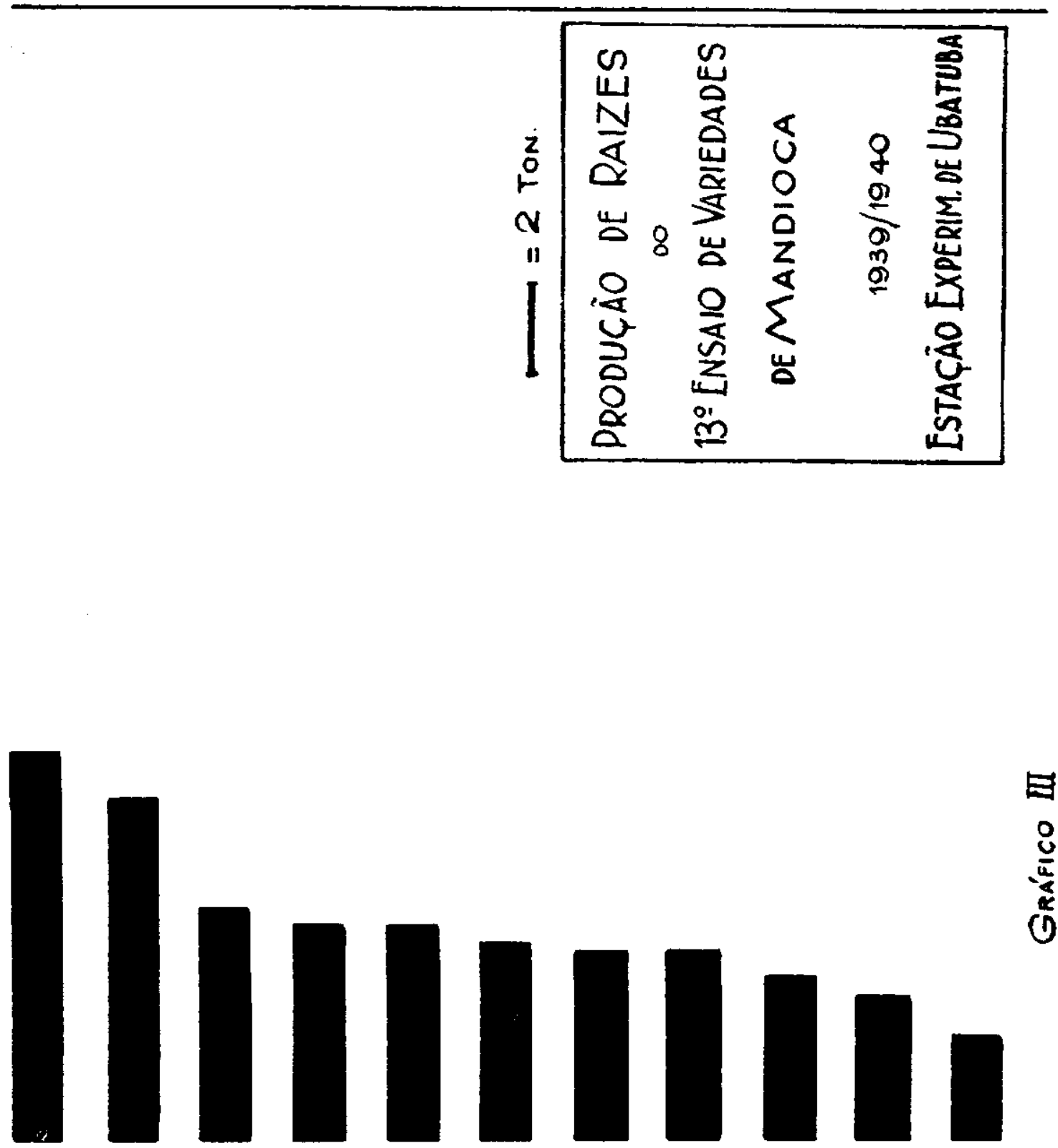

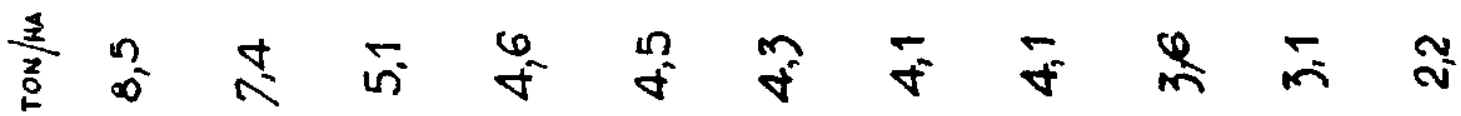

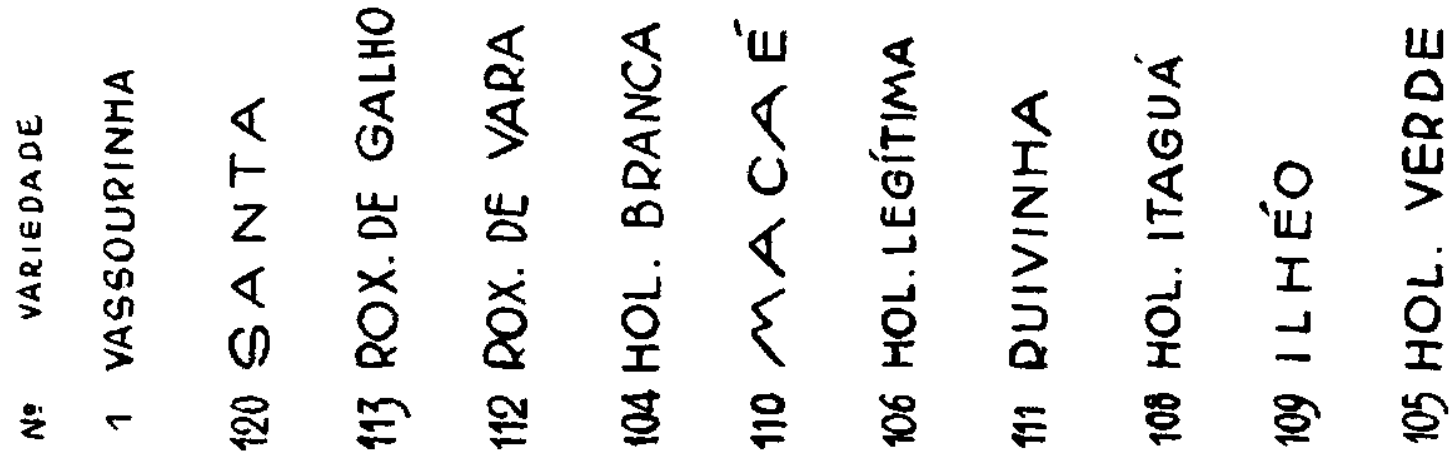


As diferenças de produções foram significativas mesmo para $\mathrm{P}=1 \%$. Considerando $\mathrm{P}=5 \%$, a diferença mínima significativa encontrada para a comparação de dois tratamentos entre si, foi de $10,0 \mathrm{Kg}$.

A variedade n. 1 - "Vassourinha" - foi, em produção de farinha, superior a todas; a de n. ${ }^{\circ} 120$ - "Santa", superior às de n. ${ }^{\circ}$ s 112 , $113,110,111,109$, e a de n. ${ }^{\circ} 108$ superior apenas à de n." 109.

Comparando-se as produções brutas em $\mathrm{Kg}$ de raizes colhidos com I e com 2 ciclos vegetativos, para cada variedade (confronto entre os ensaios $8 .^{\circ}$ e $7 .^{\circ}$ respectivamente), observa-se que houve aumento de produção, maior ou menor, de acordo com a variedade considerada, exceção feita apenas para as variedades n. ${ }^{\circ} \mathrm{s} 111$ - Ruivinha - e 109 - Ilhéu - que acusaram produções pouco menores.

Conforme se pode ver pelos quadros VII e XI relativos a esses dois ensaios, somente as variedades $n .{ }^{\circ} \mathrm{S} 1$ - Vassourinha - e 120 - Santa - apresentaram um aumento apreciavel de produção no segundo ciclo vegetativo.

Fato idêntico se deu com a produção de farinha.

\section{3.' ENSAIO}

Plantio em : 29 de setembro de 1939

Colheita em: julho de 1940

Ciclo vegetativo: 10 meses

Variedades estudadas: as mesmas 11 já citadas.

O "stand" foi bom para todos os canteiros.

A análise estatística das produções de $\mathrm{Kg}$ de raizes por canteiro, apresentou os resultados representados nos quadros XV e XVI engráfico III. 


\section{QUADRO XV}

\begin{tabular}{|c|c|c|c|c|c|c|c|}
\hline \multirow{3}{*}{$\begin{array}{l}\text { Var. } \\
\text { N. }{ }^{\circ}\end{array}$} & \multicolumn{4}{|c|}{$\mathrm{Kg}$ por canteiro } & \multirow{3}{*}{$\begin{array}{l}\text { Médias } \\
\qquad \mathrm{Kg}\end{array}$} & \multirow{2}{*}{\multicolumn{2}{|c|}{ Ton por }} \\
\hline & \multicolumn{4}{|c|}{ SÉRIES } & & & \\
\hline & $l^{\mathrm{a}}$ & $2^{\mathrm{a}}$ & $3^{a}$ & $4^{a}$ & & Ha. & Alq \\
\hline 1 & 58,9 & 64,5 & 51,0 & 71,2 & 61,4 & 8,5 & 20,6 \\
\hline 120 & 56,0 & 57,5 & 61,0 & 37,5 & 53,0 & 7,4 & 17,9 \\
\hline 113 & 38,5 & 30,5 & 42,0 & 35,5 & 36,6 & 5,1 & 12,3 \\
\hline 112 & 37,0 & 37,5 & 23,0 & 36,0 & 33,4 & 4,6 & 11,1 \\
\hline 104 & 38,0 & 35,0 & 18,0 & 40,0 & 32,7 & 4,5 & 10,9 \\
\hline 110 & 29,0 & 34,0 & 37,5 & 23,5 & 31,0 & 4,3 & 10,4 \\
\hline 106 & 33,5 & 28,5 & 29,5 & 27,5 & 29,7 & 4,1 & 9,9 \\
\hline 111 & 25,5 & 32,0 & 26,5 & 34,5 & 29,6 & 4,1 & 9,9 \\
\hline 108 & 25,0 & 38,2 & 22,8 & 17,5 & 25,9 & 3,6 & 8,7 \\
\hline 109 & 25,0 & 19,0 & 24,0 & 21,0 & 22,2 & 3,1 & 7,5 \\
\hline 105 & 16,5 & 11,0 & 21,5 & 14,5 & 15,9 & 2,2 & 5,3 \\
\hline
\end{tabular}

\section{QUADRO XVI}

ANÁLISE DA VARIANCE

\begin{tabular}{|c|c|c|c|c|c|c|}
\hline VARIAÇন̃O & $\mathrm{Sd}^{2}$ & $\mathrm{n}_{\mathrm{f}}$ & $\mathrm{s}^{2}$ & $s$ & $\vartheta$ & \\
\hline Total & 8368,71 & 43 & 194,62 & 13,95 & 1,97 & \\
\hline Variedades & 6795,38 & 10 & 679,54 & 26,07 & 3,68 & s. \\
\hline Repetições & 70,22 & 3 & 23,41 & 4,83 & 1,46 & \\
\hline Resíduo .. & 1503,11 & 30 & 50,10 & 7,08 & & \\
\hline
\end{tabular}

$s .=$ significativo $s_{v}=3,54$ 
Houve diferença estatística entre as variedades, mesmo para $\mathrm{P}=1 \%$. Para $\mathrm{P}=5 \%$ a diferença mínima significativa encontrada é $12,2 \mathrm{Kg}$.

Conclusão deste ensaio: Variedades n. ${ }^{\circ} \mathrm{s} 1$ - Vassourinha - e 120 - Santa - superiores; variedades n.s 108 - Holandí Itaguá 109 - Ilhéu - e 105 - Holandí Verde - inferiores; as demais formam uma série homogênea quanto à produção.

Dadas as pequenas produções de raizes obtidas por canteiro, o que dificultava a sua industrialização separadamente, a fabricação de farinha foi feita apenas com o total de cada variedade ( 4 séries).

Pelo quadro XVII se pode ver perfeitamente que a variedade n. ${ }^{\circ} 1$ - Vassourinha - produziu mais do dobro do peso de farinha do que as demais variedades, exceção feita das de n. ${ }^{\circ}$ s. 120 e 113.

No quadro seguinte damos os valores numéricos das produções médias de farinha (quadro XVII) :

QUADRO XVII

\begin{tabular}{|c|c|c|c|c|}
\hline \multirow{2}{*}{$\begin{array}{l}\text { Var. } \\
\text { N. }\end{array}$} & \multirow{2}{*}{$\begin{array}{c}\text { Médias } \\
\text { Kg }\end{array}$} & \multicolumn{2}{|c|}{ Ton por } & \multirow{2}{*}{$\begin{array}{l}\% \text { de } \\
\text { farinha }\end{array}$} \\
\hline & & $\mathrm{Ha}$. & Alg. & \\
\hline $\begin{array}{r}1 \\
120 \\
113 \\
112 \\
110 \\
111 \\
104 \\
106 \\
108 \\
109 \\
105\end{array}$ & $\begin{array}{r}17,5 \\
11,2 \\
9,4 \\
8,7 \\
8,1 \\
8,0 \\
7,9 \\
7,7 \\
6,7 \\
5,4 \\
4,4\end{array}$ & $\begin{array}{l}2,4 \\
1,5 \\
1,3 \\
1,2 \\
1,1 \\
1,1 \\
1,1 \\
1,1 \\
0,9 \\
0,7 \\
0,6\end{array}$ & $\begin{array}{l}5,8 \\
3,7 \\
3,1 \\
2,9 \\
2,7 \\
2,7 \\
2,6 \\
2,6 \\
2,2 \\
1,8 \\
1,5\end{array}$ & $\begin{array}{l}28,5 \\
21,1 \\
25,7 \\
26,0 \\
26,1 \\
27,0 \\
24,1 \\
25,9 \\
25,9 \\
24,3 \\
27,7\end{array}$ \\
\hline
\end{tabular}

\section{ENSAIO}

Plantio em: 16 de agosto de 1940

Colheita em: agosto de 1941

Ciclo vegetativo: 1 ano

As variedades estudadas foram as mesmas 11 já citadas.

$O$ "stand" foi, de um modo geral, bom para todas as variedades, entretanto a de n. 120 -- Santa - apresentou 23\% de falhas.

Produções de raizes obtidas (quadros XVIII e XIX e gráfico IV) 

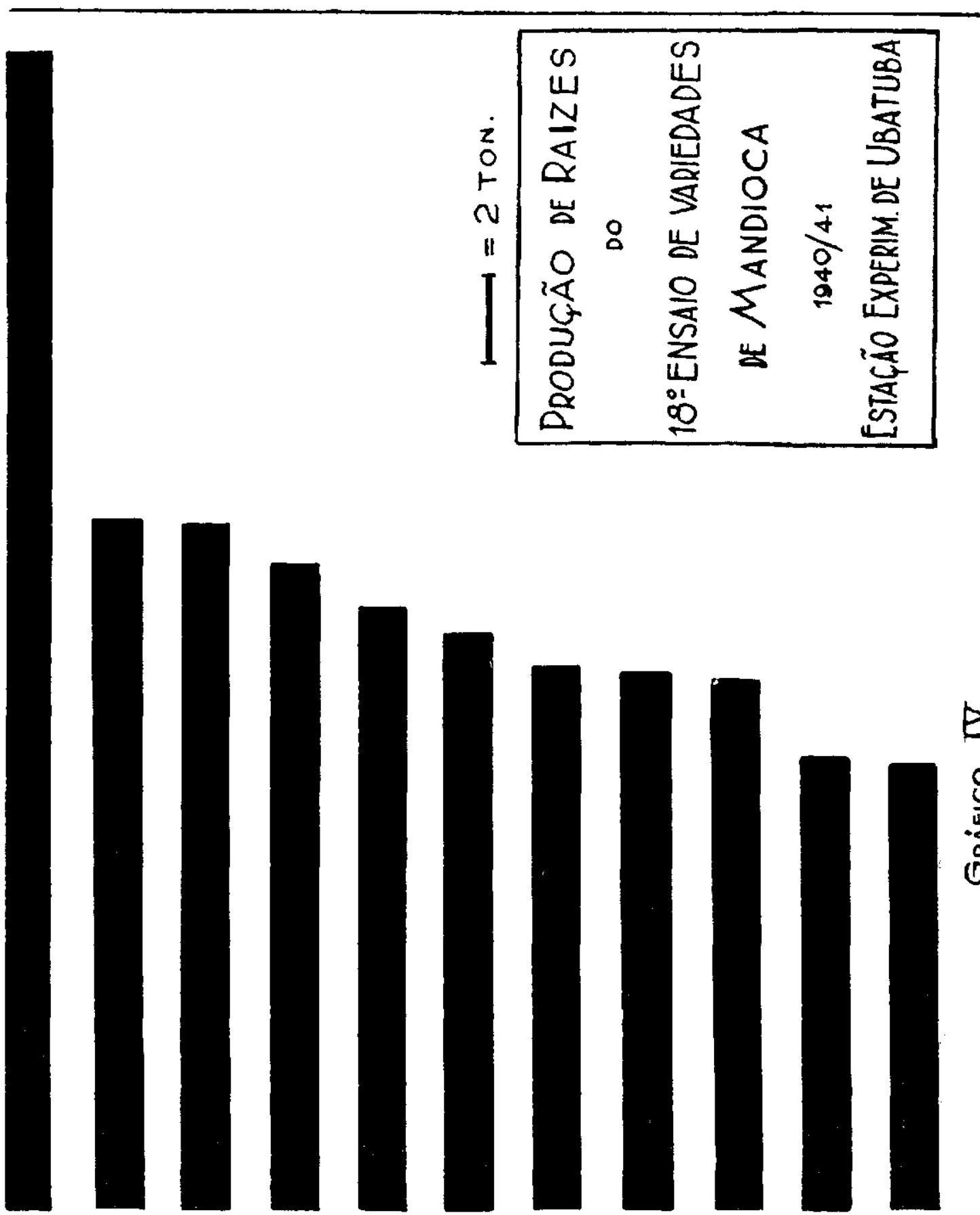

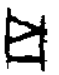

I $\quad 0$ \%

$\stackrel{\infty}{m}$

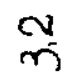

iิ

$\bar{\Phi}$
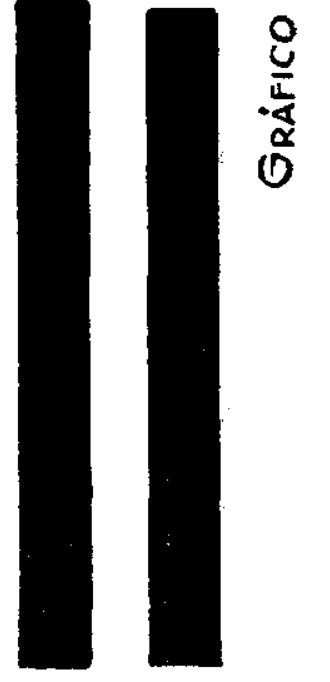

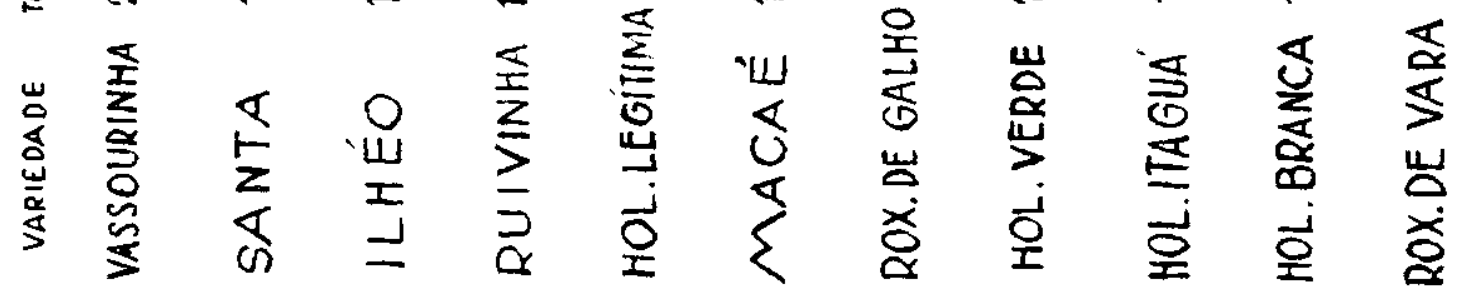
㞫 -
s)
$\equiv 8$
을
$\cong$
$\stackrel{2}{2}$
: 
QUADRO XVIII

\begin{tabular}{|c|c|c|c|c|c|c|c|}
\hline \multirow{3}{*}{$\begin{array}{l}\text { Var. } \\
\text { N." }\end{array}$} & \multicolumn{4}{|c|}{$\mathrm{Kg}$ por canteiro } & \multirow{3}{*}{$\begin{array}{c}\text { Médias } \\
\text { Kg. }\end{array}$} & \multirow{2}{*}{ Ton } & \multirow{2}{*}{ por } \\
\hline & \multicolumn{4}{|c|}{ SERIES } & & & \\
\hline & $l^{a}$ & $2^{a}$ & $3:$ & $4^{: n}$ & & $\mathrm{Ha}$. & Alq. \\
\hline 1 & 165,0 & 199,5 & 182,9 & 212,6 & 190,0 & 26,4 & 63,9 \\
\hline 120 & 110,7 & 124,8 & 114,8 & 101,4 & 112,9 & 15,7 & 38,0 \\
\hline 109 & 102,5 & 118,9 & 108,1 & 120,8 & 112,6 & 15,6 & 37,7 \\
\hline 111 & 109,4 & 109,5 & 98,2 & 105,5 & 105,7 & 14,7 & 35,6 \\
\hline 106 & 101,4 & 91,3 & 98,4 & 105,9 & 99,3 & 13,8 & 33,4 \\
\hline 110 & 88,1 & 100,1 & 91,8 & 100,1 & 95,0 & 13,2 & 31,9 \\
\hline 113 & 97,1 & 90,5 & 76,1 & 95,9 & 89,9 & 12,5 & 30,2 \\
\hline 105 & 69,0 & 82,0 & 92,8 & 110,5 & 88,6 & 12,3 & 29,8 \\
\hline 108 & 78,6 & 95,4 & 86,2 & 87,6 & 87,0 & 12,1 & 29,3 \\
\hline 104 & 49,4 & 60,0 & 96,4 & 92,4 & 74,6 & 10,4 & 25,2 \\
\hline 112 & 68,1 & 67,5 & 78,3 & 81,4 & 73,8 & 10,2 & 24,7 \\
\hline
\end{tabular}

QUADRO XIX

ANÁLISE DA VARIANCE

\begin{tabular}{|c|c|c|c|c|c|c|}
\hline VARIAÇÃO & $\mathrm{Sd}^{2}$ & $\mathrm{n}_{\mathrm{f}}$ & $\mathrm{s}^{2}$ & s & $\vartheta$ & \\
\hline Total & 45792,95 & 43 & 1064,95 & 32,63 & 2,89 & \\
\hline Variedades & 40561,81 & 10 & 4056,18 & 63,69 & 5,64 & s. \\
\hline Repetições & 1402,10 & 3 & 465,53 & 21,58 & 1,91 & \\
\hline Resíduo & 3829,04 & 30 & 127,63 & 11,30 & & \\
\hline
\end{tabular}

$\mathrm{s} .=$ significativo $\overrightarrow{\mathrm{s}_{\mathrm{v}}}=5,65$ 
O ensaio foi significativo, mesmo para $1 \%$ de probabilidade.

A diferença mínima significativa para $\mathrm{P}=5 \%$ foi de $19,6 \mathrm{Kg}$.

As variedades n.os 1, 120 e 109 foram superiores; as de n. "s 104 e 112 inferiores.

No grupo das superiores, a variedade n. 1 -- Vassourinha - é a única que se destaca como superior a todas, inclusive as outras duas do seu grupo.

$\mathrm{O}$ quadro XX traz a relação das produções de farinha obtidas neste ensaio. A farinha foi feita com a produção total de raizes das 4 repetições, para cada variedade:

\section{QUADRO XX}

\begin{tabular}{|c|c|c|c|c|}
\hline \multirow{2}{*}{$\begin{array}{l}\text { Var. } \\
\text { N." }\end{array}$} & \multirow{2}{*}{$\begin{array}{c}\text { Médias } \\
\mathrm{Kg} \text {. }\end{array}$} & \multicolumn{2}{|c|}{ Ton por } & \multirow{2}{*}{$\begin{array}{l}\% \text { de } \\
\text { Farinha }\end{array}$} \\
\hline & & $\mathrm{Ha}$. & Alq. & \\
\hline $\begin{array}{r}1 \\
120 \\
109 \\
111 \\
106 \\
105 \\
113 \\
108 \\
110 \\
112 \\
104\end{array}$ & $\begin{array}{l}59,6 \\
27,6 \\
27,4 \\
27,3 \\
25,4 \\
24,6 \\
23,3 \\
23,2 \\
22,9 \\
19,5 \\
19,2\end{array}$ & $\begin{array}{l}8,3 \\
3,8 \\
3,8 \\
3,8 \\
3,5 \\
3,4 \\
3,2 \\
3,2 \\
3,2 \\
2,7 \\
2,7\end{array}$ & $\begin{array}{r}20,1 \\
9,2 \\
9,2 \\
9,2 \\
8,5 \\
8,2 \\
7,7 \\
7,7 \\
7,7 \\
6,5 \\
6,5\end{array}$ & $\begin{array}{l}31,4 \\
24,4 \\
24,3 \\
25,8 \\
25,6 \\
27,8 \\
25,9 \\
26,7 \\
24,1 \\
26,4 \\
25,7\end{array}$ \\
\hline
\end{tabular}

Dos resultados acima depreende-se que a variedade n." 1 - Vassourinha - produziu o dobro de farinha, em relação às demais variedades. Foi tambem a que apresentou melhor rendimento de farinha.

19." ENSAIO

Plantio em : 17 de agosto de 1940

Colheita em: agosto de 1942

Ciclo vegetativo: 2 anos.

As variedades estudadas foram as mesmas 11 , já citadas.

Com exceção das variedades n.os 113 e 108 , que tiveram respectivamente $42 \%$ e $36 \%$ de falhas, as demais apresentaram de 15 a $20 \%$.

Cálculo das produções de raizes obtidas (quadros XXI e XXII e grafico V) 


\section{QUADRO XXI}

\begin{tabular}{|c|c|c|c|c|c|c|c|}
\hline \multirow{3}{*}{$\begin{array}{l}\text { Var. } \\
\text { N." }\end{array}$} & \multicolumn{4}{|c|}{$\mathrm{Kg}$ por canteiro } & \multirow{3}{*}{$\begin{array}{c}\text { Médias } \\
\text { Kg }\end{array}$} & \multirow{2}{*}{\multicolumn{2}{|c|}{ Ton por }} \\
\hline & \multicolumn{4}{|c|}{ SERIES } & & & \\
\hline & $1:$ & $2 w$ & $3:$ & 4:" & & Ha. & Alq. \\
\hline 120 & 204,0 & 200,0 & 203,0 & 212,0 & 204,7 & 28,4 & 68,7 \\
\hline 1 & 171,0 & 200,0 & 104,0 & 93,0 & 142,0 & 19,7 & 47,7 \\
\hline 105 & 100,0 & 128,0 & 194,0 & 66,0 & 122,0 & 16,9 & 40,9 \\
\hline 111 & 106,0 & 138,0 & 106,0 & 93,0 & 110,7 & 15,4 & 37,3 \\
\hline 110 & 126,0 & 72,0 & 135,0 & 82,0 & 103,7 & 14,4 & 34,8 \\
\hline 104 & 104,0 & 135,0 & 74,0 & 77,0 & 97,5 & 13,5 & 32,7 \\
\hline 106 & 106,0 & 88,0 & 108,0 & 80,0 & 95,5 & 13,3 & 32,2 \\
\hline 108 & 111,0 & 128,0 & 74,0 & 60,0 & 93,2 & 12,9 & 31,2 \\
\hline 112 & 80,0 & 100,0 & 98,0 & 90,0 & 92,0 & 12,8 & 31,0 \\
\hline 109 & 33,5 & 103,0 & 99,0 & 94,0 & 82,4 & 11,4 & 27,6 \\
\hline 113 & 65,0 & 111,0 & 78,0 & 63,0 & 79,2 & 11,0 & 26,6 \\
\hline
\end{tabular}

\section{QUADRO XXII}

ANÁLISE DA VARIANCE

\begin{tabular}{|c|c|c|c|c|c|c|}
\hline VARIAÇÃO & $S d^{2}$ & $\mathrm{n}_{\mathrm{f}}$ & $s^{2}$ & $\mathrm{~s}$ & 9 & \\
\hline Total & 80809,86 & 43 & 1879,29 & 43,35 & 1,60 & \\
\hline Variedades & 51397,17 & 10 & 5139,71 & 71,69 & 2,64 & s. \\
\hline Repetições & 7321,92 & 3 & 2440,64 & 49,40 & 1,82 & \\
\hline Resíduo & 22090,77 & 30 & 736,36 & 27,13 & & \\
\hline
\end{tabular}

$\mathrm{s.}=$ significativo $\mathrm{s}_{\mathrm{v}}^{-}=13,57$ 


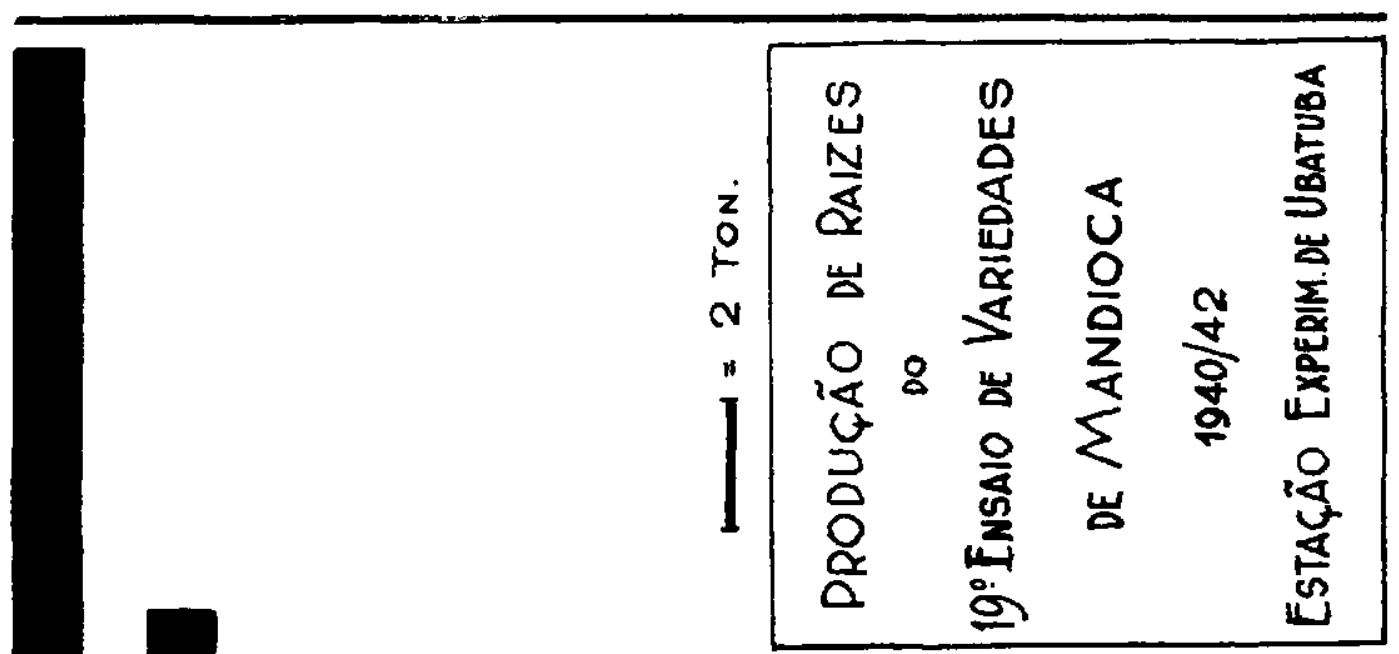

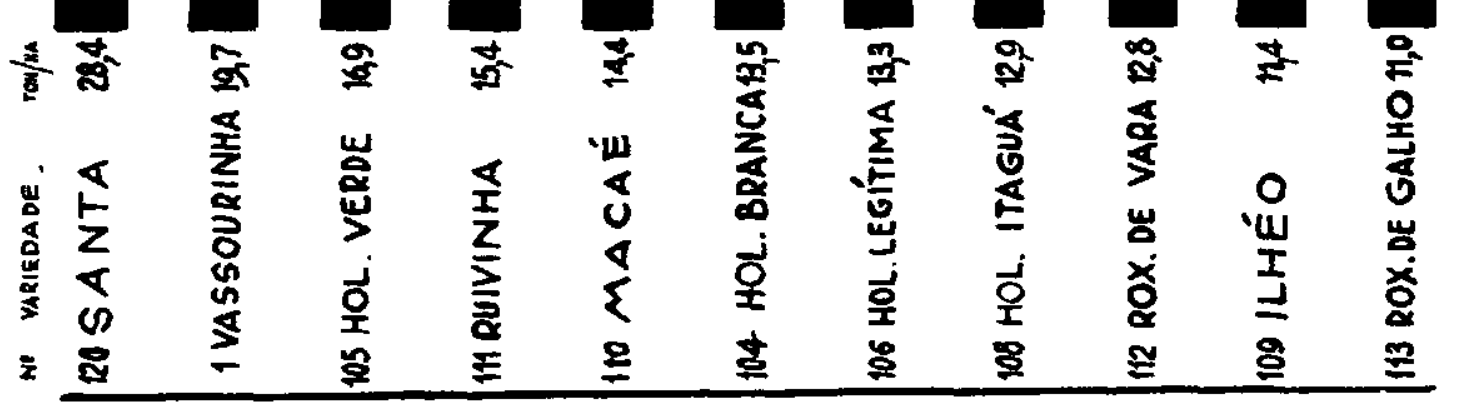


Houve diferença estatística de produção entre as variedades.

Para $\mathrm{P}=5 \%$, a diferença mínima significativa encontrada foi 47,0 Kg, a qual permite separar as variedades em:

Superiores: $n .^{\text {os }} 1$ e 120

Inferiores : n.os $108-109-112$ e 113.

Devemos fazer a seguinte observação:

Neste ensaio a variedade n. 120 - Santa - mostrou-se superior em produção, a todàs as outras, inclusive mesmo a "Vassourinha" que, nas experiências anteriormente citadas, ocupou o primeiro lugar.

A industrialização das raizes obtidas, em farinha de mesa, foi feita com o total das 4 repetições, para cada variedade, fornecendo o resultado que está contido no quadro XXIII.

\section{QUADRO XXIII}

\begin{tabular}{|c|c|c|c|c|}
\hline \multirow{2}{*}{$\begin{array}{l}\text { Var. } \\
\text { N." }\end{array}$} & \multirow{2}{*}{$\begin{array}{c}\text { Médias } \\
\text { Kg }\end{array}$} & \multicolumn{2}{|c|}{ Ton por } & \multirow{2}{*}{$\begin{array}{l}\% \text { de } \\
\text { farinha }\end{array}$} \\
\hline & & Ha. & Alq. & \\
\hline $\begin{array}{r}120 \\
1 \\
105 \\
111 \\
110 \\
104 \\
108 \\
112 \\
109 \\
106 \\
113\end{array}$ & $\begin{array}{l}64,7 \\
37,2 \\
35,0 \\
27,5 \\
27,5 \\
27,5 \\
25,0 \\
24,2 \\
22,5 \\
20,9 \\
20,0\end{array}$ & $\begin{array}{l}9,0 \\
5,2 \\
4,9 \\
3,8 \\
3,8 \\
3,8 \\
3,5 \\
3,4 \\
3,1 \\
2,9 \\
2,8\end{array}$ & $\begin{array}{r}21,8 \\
12,5 \\
11,8 \\
9,2 \\
9,2 \\
9,2 \\
8,4 \\
8,2 \\
7,5 \\
7,0 \\
6,7\end{array}$ & $\begin{array}{l}31,6 \\
26,2 \\
28,7 \\
24,8 \\
26,5 \\
28,2 \\
26,8 \\
26,3 \\
27,3 \\
21,9 \\
25,2\end{array}$ \\
\hline
\end{tabular}

Conforme se vê nesse ensaio, a variedade n. 120 - Santa - apresentou tambem maior produção e maior rendimento de farinha.

\section{RESUMO DOS ENSAIOS}

Os quadros XXIV e XXV e os gráficos VI e VII - mostram os resultados, para cada ensaio, das produções médias em raizes e farinha, respectivamente, na base de toneladas por hectare: 

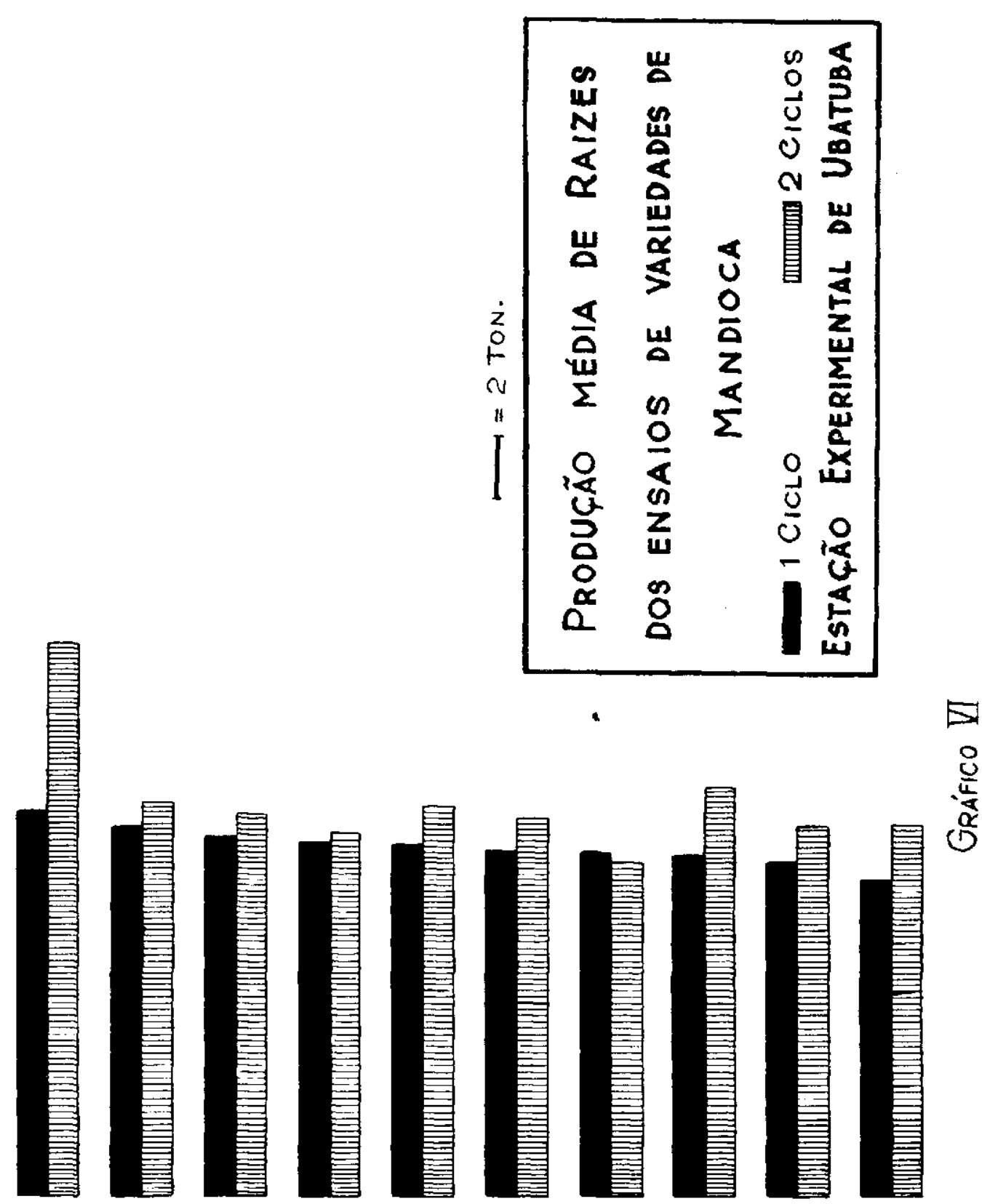

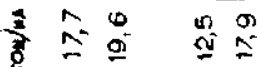

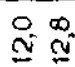

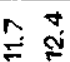

$\stackrel{n}{=} \stackrel{\infty}{=}$

$\stackrel{\forall}{=} \mathrm{i}$

$\stackrel{N}{=} \stackrel{m}{N}$

$\stackrel{0}{=}$

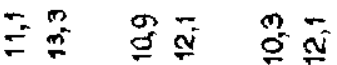

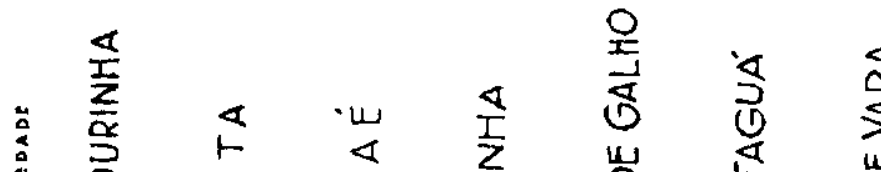

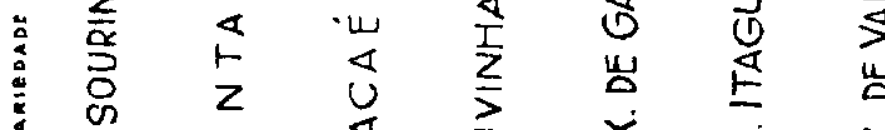

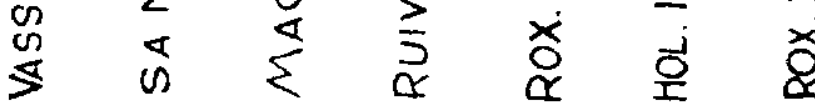

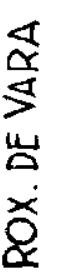

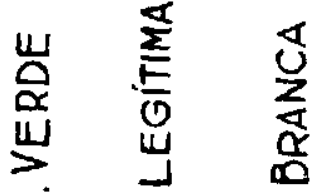

U $>$

온

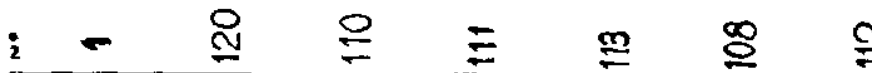


QUADRO XXIV

\begin{tabular}{|c|c|c|c|c|c|c|c|c|c|}
\hline \multirow{2}{*}{$\begin{array}{l}\text { Var. } \\
\text { N." }\end{array}$} & \multicolumn{5}{|c|}{$\begin{array}{l}\text { Ensaios colhidos com } \\
\text { l ciclo vegetativo }\end{array}$} & \multicolumn{3}{|c|}{$\begin{array}{l}\text { Ensaios colhidos com } \\
2 \text { ciclos vegetativos }\end{array}$} & \multirow{2}{*}{$\begin{array}{l}\text { Média } \\
\text { geral }\end{array}$} \\
\hline & $l^{\prime \prime}$ & $8^{\circ}$ & $13^{\prime \prime}$ & $18^{\circ}$ & Médias & $7^{\circ}$ & $19^{\circ}$ & Médias & \\
\hline 1 & - & 18,2 & 8,5 & 26,4 & 17,7 & 23,5 & 19,7 & 21,6 & 19,6 \\
\hline 104 & 13,0 & 13,4 & 4,5 & 10,4 & 10,3 & 14,5 & 13,5 & 14,0 & 12,1 \\
\hline 105 & 13,8 & 16.1 & 2,2 & 12,3 & 11,1 & 14,4 & 16,9 & 15,6 & 13,3 \\
\hline 106 & - & 14,7 & 4,1 & 13,8 & 10,9 & 13,6 & 13,3 & 13,4 & 12,1 \\
\hline 108 & 15,2 & 14,7 & 3.6 & 12,1 & 11,4 & 15,2 & 12,9 & 14,0 & 12,7 \\
\hline 109 & 14,8 & - & 3,1 & 15,6 & 11,2 & 10,1 & 11,4 & 10,7 & 10,9 \\
\hline 110 & 14,2 & 16,2 & 4,3 & 13,2 & 12,0 & 13,0 & 14,4 & 13,7 & 12,8 \\
\hline 111 & 14,2 & 13,8 & 4,1 & 14,7 & 11,7 & 10,9 & 15,4 & 13,1 & 12,4 \\
\hline 112 & 14,5 & 15,6 & 4,6 & 10,2 & 11,2 & 14,0 & 12,8 & 13,4 & 12,3 \\
\hline 113 & 13,7 & 14,7 & 5,1 & 12,5 & 11,5 & 13,4 & 11,0 & 12,2 & 11,8 \\
\hline 120 & 12,6 & 14,5 & 7,4 & 15,7 & 12,5 & 18,2 & 28,4 & 23,3 & 17,9 \\
\hline
\end{tabular}

QUADRO XXV

\begin{tabular}{|c|c|c|c|c|c|c|c|c|c|}
\hline \multirow{2}{*}{$\begin{array}{l}\text { Var. } \\
\text { N." }\end{array}$} & \multicolumn{5}{|c|}{$\begin{array}{l}\text { Ensaios colhidos com } \\
\text { l ciclo vegetativo }\end{array}$} & \multicolumn{3}{|c|}{$\begin{array}{l}\text { Ensaios colhidos com } \\
2 \text { ciclos vegetativos }\end{array}$} & \multirow{2}{*}{$\begin{array}{l}\text { Média } \\
\text { geral }\end{array}$} \\
\hline & $1^{\circ}$ & $8^{\circ}$ & $13^{\circ}$ & $18^{\circ}$ & Médias & $7^{\circ}$ & $19^{\circ}$ & Médias & \\
\hline 1 & - & 4,0 & 2,4 & 8,3 & 4,9 & 7,3 & 5,2 & 6,2 & 5,5 \\
\hline 104 & 3,3 & 3,5 & 1,1 & 2,7 & 2,6 & 4,1 & 3,8 & 3,9 & 3,2 \\
\hline 105 & 3,7 & 3,8 & 0,6 & 3,4 & 2,9 & 4,4 & 4,9 & 4,6 & 3,7 \\
\hline 106 & - & 3,7 & 1,1 & 3,5 & 2,8 & 4,0 & 2,9 & 3,4 & 3,1 \\
\hline 108 & 3,9 & 3,9 & 0,9 & 3,2 & 3,0 & 4,4 & 3,5 & 3,9 & 3,4 \\
\hline 109 & 3,9 & - & 0,7 & 3,8 & 2,8 & 2,9 & 3,1 & 3,0 & 2,9 \\
\hline 110 & 3,7 &, 38 & 1,1 & 3,2 & 2,9 & 3,7 & 3,8 & 3,7 & 3,3 \\
\hline 111 & 3,7 & 3,3 & 1,1 & 3,8 & 3,0 & 3,2 & 3,8 & 3,5 & 3,3 \\
\hline 112 & 3,2 & 3,5 & 1,2 & 2,7 & 2,6 & 3,8 & 3,4 & 3,6 & 3,1 \\
\hline 113 & 3,9 & 3,8 & 1,3 & 3,2 & 3,0 & 3,8 & 2,8 & 3,3 & 3,1 \\
\hline 120 & 2,5 & 2,9 & 1,5 & 3,8 & 2,7 & 5,3 & 9,0 & 7,1 & 4,9 \\
\hline
\end{tabular}

Para se concluir a respeito da produtividade relativa das variedades de mandioca estudadas, no tocante a raizes e farinha, o quadro XXVI mostra os resultados sumários de cada ensaio: 


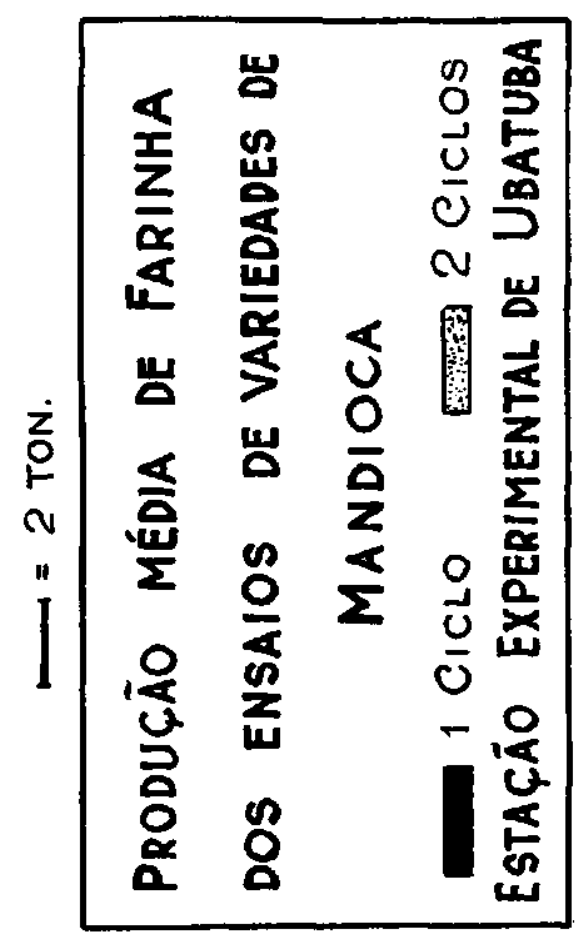

ํㅜㅇ ำ
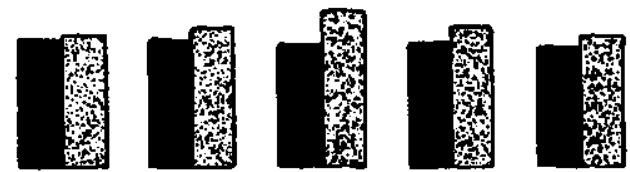

i?

$\infty-$
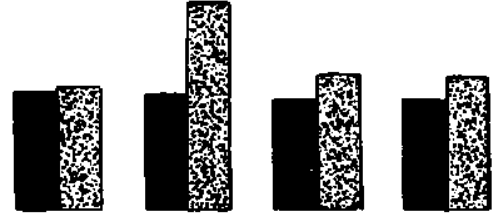

$\stackrel{2}{\circ}$

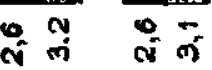

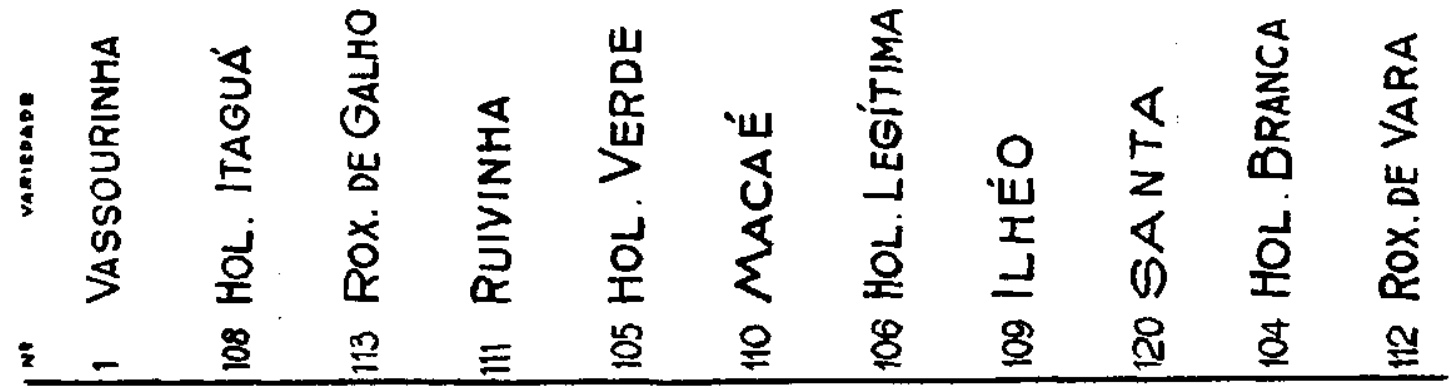


QUADRO XXVI

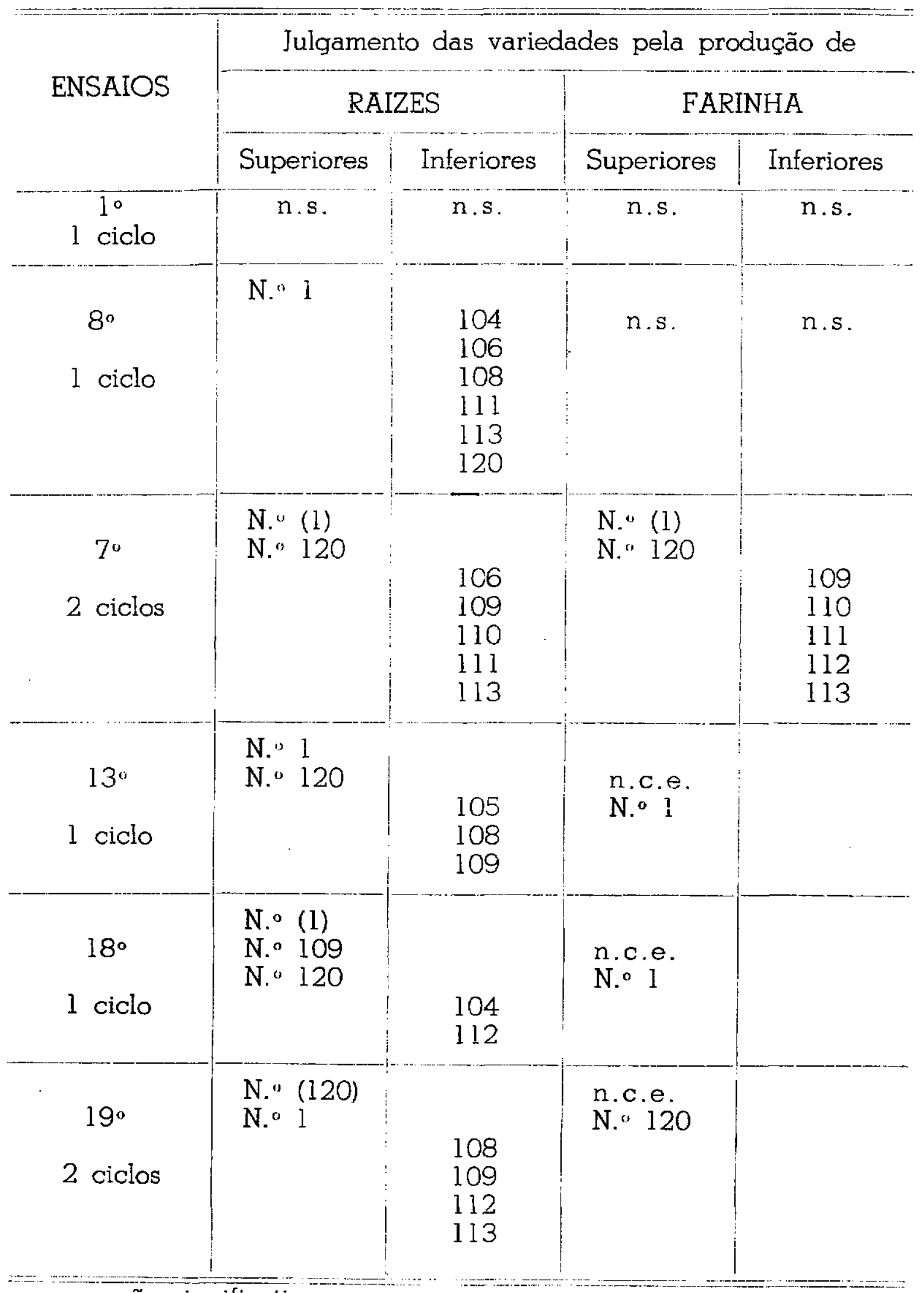

n.s. $=$ não significativo

n.c.e. $=$ não calculado estatísticamente. 
Com as conclusões já tiradas de cada experiência, podemos agora interpretar os nossos resultados pelo exame do quadro XXVI. Nele fazemos o julgamento das variedades, de um lado pela sua produção em raizes, e de outro pela de farinha.

Tanto para um como para outro caso, damos, em colunas, os números das variedades "superiores" e das "inferiores".

O parênteses colocado em alguns números das colunas intituladas "superiores", indica que a variedade assinalada é superior estatísticamente, em produção, a todas as demais, inclusive, portanto, as que figuram na mesma coluna. As que não estão assinaladas são superiores apenas às constantes das colunas "inferiores".

Pelo exame do quadro se deduz que as variedades n.os 1 - Vassourinha - e 120 - Santa - foram as melhores, e que destas duas, a n. ${ }^{\circ} 1$ - Vassourinha - se destacou ainda, visivelmente.

Quando comparada à n. ${ }^{\circ} 1$ - Vassourinha - a n. ${ }^{\circ} 120$ - Santa - apresenta como desvantagens: produzir raizes pedunculadas, mais fibrosas, e tambem possuir a casca da raiz, de cor arroxeada, mais ou menos intensa, carater este que pode conferir coloração à farinha, depreciando-a.

\section{PRODUÇÃO DE MANIVAS DAS VARIEDADES ESTUDADAS}

Durante a colheita dos ensaios foram tomados os pesos das manivas de cada variedade, a-fim-de se ter uma idéia da sua produção por hectare, e compará-la com a de raizes.

O quadro XXVII e gráfico VIII trazem a relação das produções médias de manivas em toneladas por hectare, para cada variedade, com um e com dois ciclos vegetativos.

Pelos números apresentados pode-se ver que as variedades n.os 1 e 120 (Vassourinha e Santa) foram as que tiveram maior acréscimo na produção de ramas, de um para dois ciclos vegetativos, ou sejam de 66 e $34,1 \%$ respectivamente. 


\section{QUADRO XXVII}

\begin{tabular}{|c|c|c|c|c|c|c|c|c|c|}
\hline \multirow{2}{*}{$\begin{array}{l}\text { Var. } \\
\text { N." }\end{array}$} & \multicolumn{5}{|c|}{$\begin{array}{l}\text { Ensaios colhidos com } \\
1 \text { ciclo vegetativo }\end{array}$} & \multicolumn{3}{|c|}{$\begin{array}{l}\text { Ensaios colhidos com } \\
2 \text { ciclos vegetativos }\end{array}$} & \multirow{2}{*}{$\begin{array}{l}\text { Média } \\
\text { geral }\end{array}$} \\
\hline & 10 & $8^{\prime \prime}$ & $13^{\circ}$ & $18^{\circ}$ & Médias & $7^{\circ}$ & $19^{\circ}$ & Médias & \\
\hline $\begin{array}{r}1 \\
104 \\
105 \\
106 \\
108 \\
109 \\
110 \\
111 \\
112 \\
113 \\
120\end{array}$ & $\begin{array}{r}\overline{11,0} \\
20,5 \\
\overline{15,4} \\
8,0 \\
13,8 \\
10,5 \\
12,5 \\
11,1 \\
16,8\end{array}$ & $\begin{array}{r}8,6 \\
9,2 \\
18,5 \\
11,8 \\
10,6 \\
-10,8 \\
10,6 \\
11,7 \\
11,0 \\
12,4\end{array}$ & $\begin{array}{r}6,7 \\
7,1 \\
8,7 \\
6,7 \\
6,2 \\
7,4 \\
9,0 \\
7,1 \\
7,9 \\
7,9 \\
10,2\end{array}$ & $\begin{array}{r}16,6 \\
9,9 \\
21,2 \\
16,6 \\
15,2 \\
13,5 \\
13,9 \\
17,6 \\
14,4 \\
16,6 \\
14,8\end{array}$ & $\begin{array}{r}10,6 \\
9,3 \\
17,2 \\
11,7 \\
11,8 \\
9,6 \\
11,8 \\
11,4 \\
11,6 \\
11,6 \\
13,5\end{array}$ & $\begin{array}{r}17,1 \\
12,3 \\
19,1 \\
11,2 \\
13,2 \\
8,8 \\
16,3 \\
9,4 \\
14,4 \\
13,1 \\
14,8\end{array}$ & $\begin{array}{r}18,1 \\
12,5 \\
17,6 \\
11,4 \\
11,2 \\
11,8 \\
6,1 \\
16,5 \\
14,9 \\
12,4 \\
21,5\end{array}$ & $\begin{array}{l}17,6 \\
12,4 \\
18,3 \\
11,3 \\
12,2 \\
10,3 \\
11,2 \\
12,9 \\
14,6 \\
12,7 \\
18,1\end{array}$ & $\begin{array}{l}14,1 \\
10,8 \\
17,7 \\
11,5 \\
12,0 \\
10,0 \\
11,5 \\
12,1 \\
13,1 \\
12,1 \\
15,8\end{array}$ \\
\hline
\end{tabular}

Observa-se que, tanto com um como com dois ciclos vegetativos, a variedade n." 105 - Holandí Verde ou Grande - é a que produz mais ramas, e as de n.os 104 - Holandí Branca e 109 - Ilhéu - são as que menos produzem.

Por esses dados se pode ver que a variedade n. 105 - Holandí Verde - foi a que deu maior quantidade de ramas, mas não foi a mais produtora de raizes.

O julgamento relativo da produção das diversas variedades de mandioca não pode, pois, basear-se somente no seu aspecto vegetativo. Uma variedade de porte baixo pode ser muito mais produtiva do que outra de porte alto, ou que possua a parte vegetativa mais desenvolvida.

Entretanto, para uma mesma variedade, a produção de raizes é, no geral, função da sua parte vegetativa.

Para exemplificar o nosso caso, apontaremos o seguinte: enquanto a variedade n." I - Vassourinha -.... com 1 e com 2 ciclos vegetativos produziu, respectivamente, 167 e $123 \mathrm{Kg}$ de ramas, para cada $100 \mathrm{Kg}$ de raizes, a variedade n." 105 -.. Holandí Verde ou Grande - forneceu, nas mesmas condições, 645 e $852 \mathrm{Kg}$ de ramas. A-pesar da muito menor quantidade de ramas, a variedade n." 1 foi superior à n." 105, na produção de raizes. 


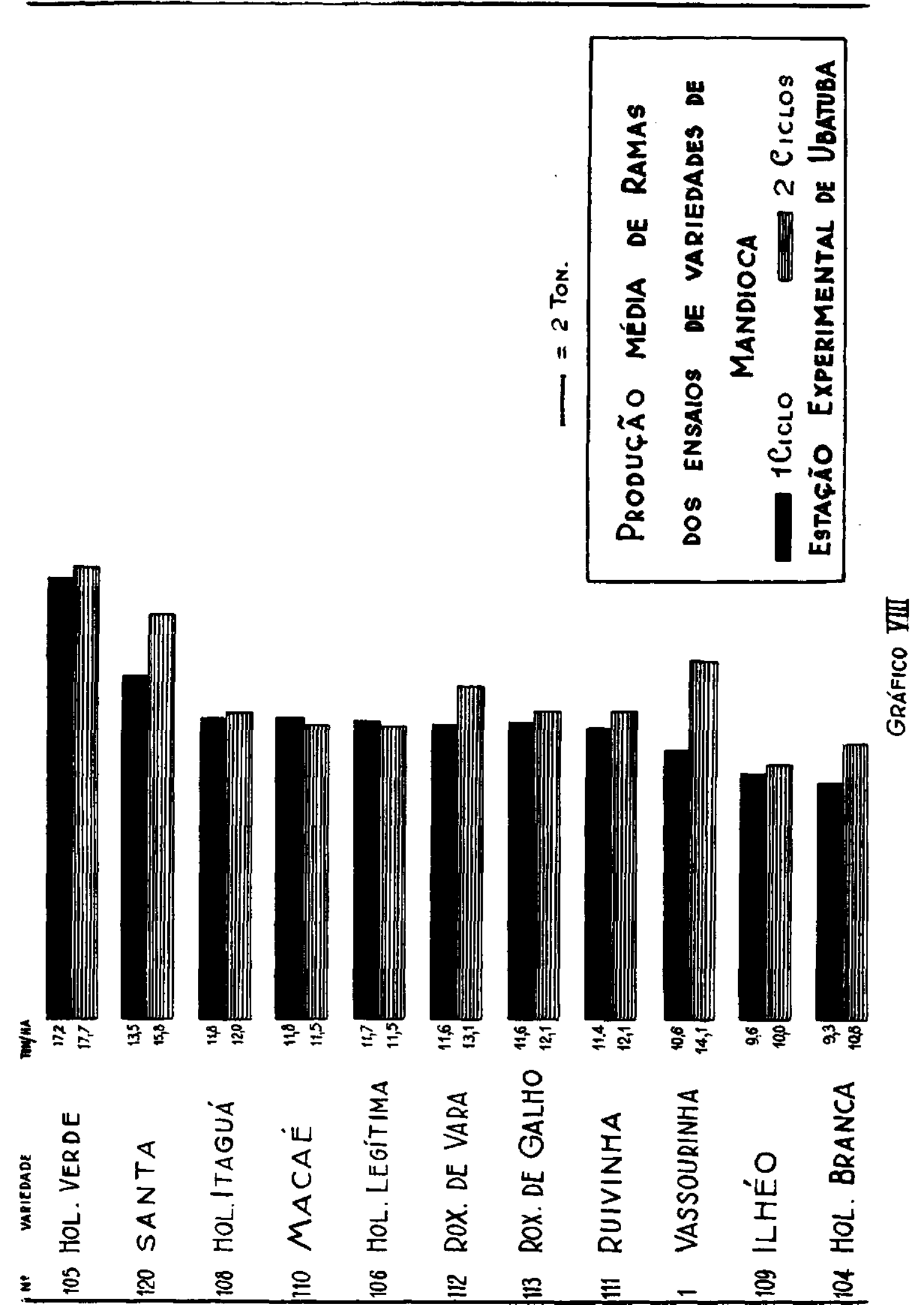




\section{ANÁLISES DAS FARINHAS}

Das farinhas obtidas nos 13." e 7." ensaios, colhidos, respectivamente, com um e com dois ciclos vegetativos, foi retirada uma amostra, representando a média de cada variedade, a-fim-de ser analisada sob o ponto de vista tecnológico.

Os quadros XXVIII e XXIX trazem os resultados das análises das farinhas provenientes das diversas variedades de mandioca, colhidas com 1 e 2 ciclos vegetativos, respectivamente. Essas análises foram feitas pela Seção de Tecnologia e Química Agrícola, do Instituto Agronômico.

QUADRO XXVIII

\begin{tabular}{c|c|c|c|c|c} 
Var. & $\begin{array}{c}\text { Umidade } \\
\text { N.0.110' }\end{array}$ & $\begin{array}{c}\text { Matéria } \\
\text { mineral }\end{array}$ & Amido & $\begin{array}{c}\text { Acidez } \\
\text { cc de } \\
\text { NaOH N/l }\end{array}$ & Celulose \\
\hline & & & & & \\
\hline 1 & 8,66 & 1,07 & 78,12 & 2,0 & 1,62 \\
104 & 8,69 & 1,17 & 77,41 & 2,5 & 1,84 \\
105 & 8,53 & 1,17 & 77,41 & 2,1 & 1,75 \\
106 & 8,04 & 1,25 & 76,70 & 3,0 & 2,00 \\
108 & 9,05 & 1,22 & 79,60 & 2,4 & 2,12 \\
109 & 8,00 & 1.26 & 78,12 & 2,6 & 2,04 \\
110 & 8,72 & 1,24 & 76,70 & 2,4 & 1,92 \\
111 & 7,76 & 1,06 & 78,12 & 2,4 & 2,58 \\
112 & 8,59 & 1,28 & 75,34 & 2,5 & 1,78 \\
113 & 7,80 & 1,21 & 78,85 & 2,5 & 1,69 \\
120 & 8,59 & 1,57 & 77,41 & 2,2 & 1,63 \\
\hline
\end{tabular}

QUADRO XXIX

\begin{tabular}{c|c|c|c|c|c} 
Var. & $\begin{array}{c}\text { Umidade } \\
\text { N. }{ }^{\circ}\end{array}$ & $\begin{array}{c}\text { Matéria } \\
\text { mineral }\end{array}$ & Amido & $\begin{array}{c}\text { Acidez } \\
\text { CC de } \\
\text { NaOH N/1 }\end{array}$ & Celulose \\
\hline & & & & & \\
\hline 1 & 8,15 & 0,93 & 78,12 & 1,9 & 1,43 \\
104 & 7,84 & 1,02 & 79,97 & 1,4 & 1,34 \\
105 & 8,52 & 0,91 & 79,97 & 2,2 & 1,54 \\
106 & 8,40 & 1,25 & 77,76 & 1,6 & 1,58 \\
108 & 8,47 & 1,09 & 77,41 & 1,7 & 1,37 \\
109 & 8,77 & 1,02 & 79,60 & 1,5 & 1,40 \\
110 & 8,50 & 1,09 & 78,12 & 1,2 & 1,38 \\
111 & 8,45 & 1,04 & 78,12 & 1,5 & 1,52 \\
112 & 8,17 & 1,06 & 77,41 & 1,6 & 1,43 \\
113 & 8,19 & 1,12 & 78,85 & 1,9 & 1,61 \\
120 & 8,62 & 1,13 & 78,85 & 1,6 & 1,45
\end{tabular}


Estas análises, são de interesse porque mostram a composição sob - ponto de vista alimentício, de farinhas que veem sendo consumidas pela população litorânea de Ubatuba.

Conforme se depreende dos resultados, aquelas farinhas são ricas em amido, cuja percentagem varia, para o conjunto das variedades, de cerca de 76 a $79 \%$, para cultura de 1 ciclo, e de 77 a $80 \%$ para a de dois ciclos vegetativos.

Aqueles números representam, em média, a composição das farinhas de mandioca para mesa, e que são, em nosso país, largamente consumidas por uma grande parte da sua população.

\section{SUMMARY}

In the present work were studied several varieties of manihot of the Ubatuba area on the north coast of the State of São Paulo. The experiments were carried out at the Experiment Station of that locality with a view to compare the production of roots and meal of each variety with that of the variety "Vassourinha", introduced in that district in 1938 by the Division of Roots and Tubers of the Instituto Agronômico. Said variety ("Vassourinha") is the most cultivated all over the State of São Paulo.

Results have shown that among the eleven varieties studied the following exceeded the others as regards production of roots and meal : N. 1 ("Vassourinha") and N. 120 ("Santa"). Comparing these two one with another, it was found that N." I surpassed N.' 120 , not only with regard to production of roots but also in regard to manufacture of meal.

Through the study of production of cuttings it was found that in no variety whatever there is a relationship between the production of stems and roots.

Finally, analyses are mentioned of meal obtained from each variety both of one and two vegetative cycles.

\section{LITERATURA CITADA}

1. Fisher, R. A. Statistical methods for research workers. 6th. Ed. pág. 1-339, Oliver and Boyd, London. 1937.

2. Brieger, F. G. Tábuas e fórmulas para Estatística. Comp. Melhoramentos de São Paulo, pág. 1-46. 1937.

3. Knoche, W. y V. Borsacov. Estudio comparativo de Climas apropriados para el Cultivo de la Caña da Azúcar según una nueva Classificacion climática. Bol. de la Estacion Exp. Agr. de Tucumán (Argentina), 30: 1-19, fig. 1. 12. Mayo, 1940. 